\title{
Catalytic Self-Threading: A New Route for the Synthesis of Polyrotaxanes
}

\author{
Dơnus Tuncel ${ }^{\dagger}$ and J oachim H. G. Steinke* \\ Department of Chemistry, Imperial College London, South Kensington Campus, \\ London SW7 2AZ, U.K. \\ Received March 8, 2003; Revised Manuscript Received September 25, 2003
}

\begin{abstract}
Main chain and branched polyrotaxanes have been synthesized in which polymerization and rotaxane formation occur simultaneously, due to the presence of the catalytically active self-threading macrocyde cucurbit[6]uril. Using monomers that contain stopper groups to prevent the catalytic macrocyde from noncatalytic threading, it was possible to prepare polyrotaxanes in high yields with molecular weights up to 39000. These polyrotaxanes are structurally perfect in the sense that exactly two macrocycles are threaded onto each structural repeat unit. Investigations into the polymerization mechanism have demonstrated that the catalyst cucurbit[6]uril is highly sensitive toward the structure of the monomers employed and a poorly designed monomer may result in complete inactivity. Features of the mechanism are discussed in some detail.
\end{abstract}

\section{Introduction}

One of the more recent polymer topologies that has received considerable attention is polyrotaxanes. ${ }^{1-6}$ Polyrotaxanes are supramolecular entities in which a macrocyclic compound is threaded onto a segment of a polymer main chain or side chain (Figure 1). The structure of the polymer threaded with the macrocycle and the strength of the noncovalent interaction between both determines if and to what extent the macrocycle can slide along the polymer main chain or side chain. ${ }^{1-5}$

This latter design feature has been exploited to prepare thermoresponsive, ${ }^{7-9}$ photoresponsi ve, ${ }^{10-13}$ and pH-responsive $\mathrm{e}^{1,14,15}$ polyrotaxanes with an ultimate application as triggerable macromolecular switching devices. The appropriate choice of macrocycle and its level of threading influences the solution-phase ${ }^{8,16-19}$ and solid-state ${ }^{16-22}$ behavior of the parent polymer, altering the solubility characteristics, $8,16-19,23-25$ phase behavior, ${ }^{8,16-19,23}$ and melt characteristics ${ }^{26}$ as well as solution viscosities $8,16-19,23,27$ at significant levels. Achieving high levels of threading to protect and insulate conducting polymer backbones is an important goal in polymer electronics. ${ }^{28}$ Biodegradable polyrotaxanes have been studied extensively for biomedical applications. ${ }^{14,29-34}$ As the sophistication of polyrotaxane syntheses increases the potential for new and unique applications increases concomitantly.

Methodologies applied to the synthesis of polyrotaxanes have improved quite dramatically since the initial statistical syntheses. ${ }^{1,35,36}$ The design of axel/macrocycle pairs with optimized steric and electronic fit, $37-40$ in conjunction with substantially more efficient and recognition-event-tolerant incorporation of stopper groups, ${ }^{41}$ has chiefly contributed to this synthetic progress. Most relevant to our investigations are main chain rotaxane architectures, which have five generic synthetic routes (Figure 2).

* To whom correspondence should be addressed. E-mail: j.steinke@imperial.ac.uk.

† Current address: Department of Chemistry, Bilkent University, SB 116, 06533 Ankara, Turkey. E-mail: dtuncel@ fen.bilkent.edu.tr.

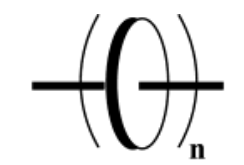

pseudopolyrotaxane

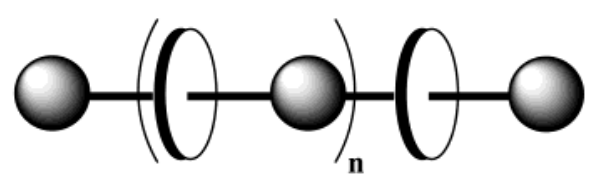

in-chain stoppered polyrotaxane
Figure 1. Definition of main chain polyrotaxanes.

Formation of a pseudopolyrotaxane via threading is strikingly simple in that a monomer is polymerized in the presence of a macrocycle, though in most cases there is little control over the number of macrocycles that can be incorporated. ${ }^{1,18,42-44}$ As an alternative to in situ polymerization, a preformed polymer can be threaded typically by mixing it with the macrocycle in solution under appropriate conditions. ${ }^{1,23,45-52}$ I n some cases the pseudopolyrotaxane precipitates during this process. F or all subsequent solution manipulations dethreading of the macrocycles becomes an issue. ${ }^{13,53,54}$ To prevent this from happening, blocking ("stopper") groups have been incorporated either at both chain ends or as an integral part of the repeat unit along the polymer main chain Classified as polyrotaxanes (Figure 2). ${ }^{55}$ An al ternative to stoppering after pseudopolyrotaxane formation ${ }^{31,56}$ is the use of prestoppered rotaxane monomers which are then polymerized ${ }^{57-62}$ or the copolymerization of selfassembled pseudorotaxane monomers with mono- or difunctional stopper groups. ${ }^{1,63-66}$ Clipping is conceptually the formation of macrocycles from linear segments in the presence of a polymer chain. This approach has been employed in various guises for the synthesis of rotaxanes, 67,68 though it so far constitutes a rarity in the synthesis of polyrotaxanes. ${ }^{69}$ Intrinsic to slipping is the presence of stopper groups along the polymer chain. Slipping was also first demonstrated in the synthesis of rotaxanes. ${ }^{36,70}$ The spatial demand of the blocking group in relation to the size of the cavity of 


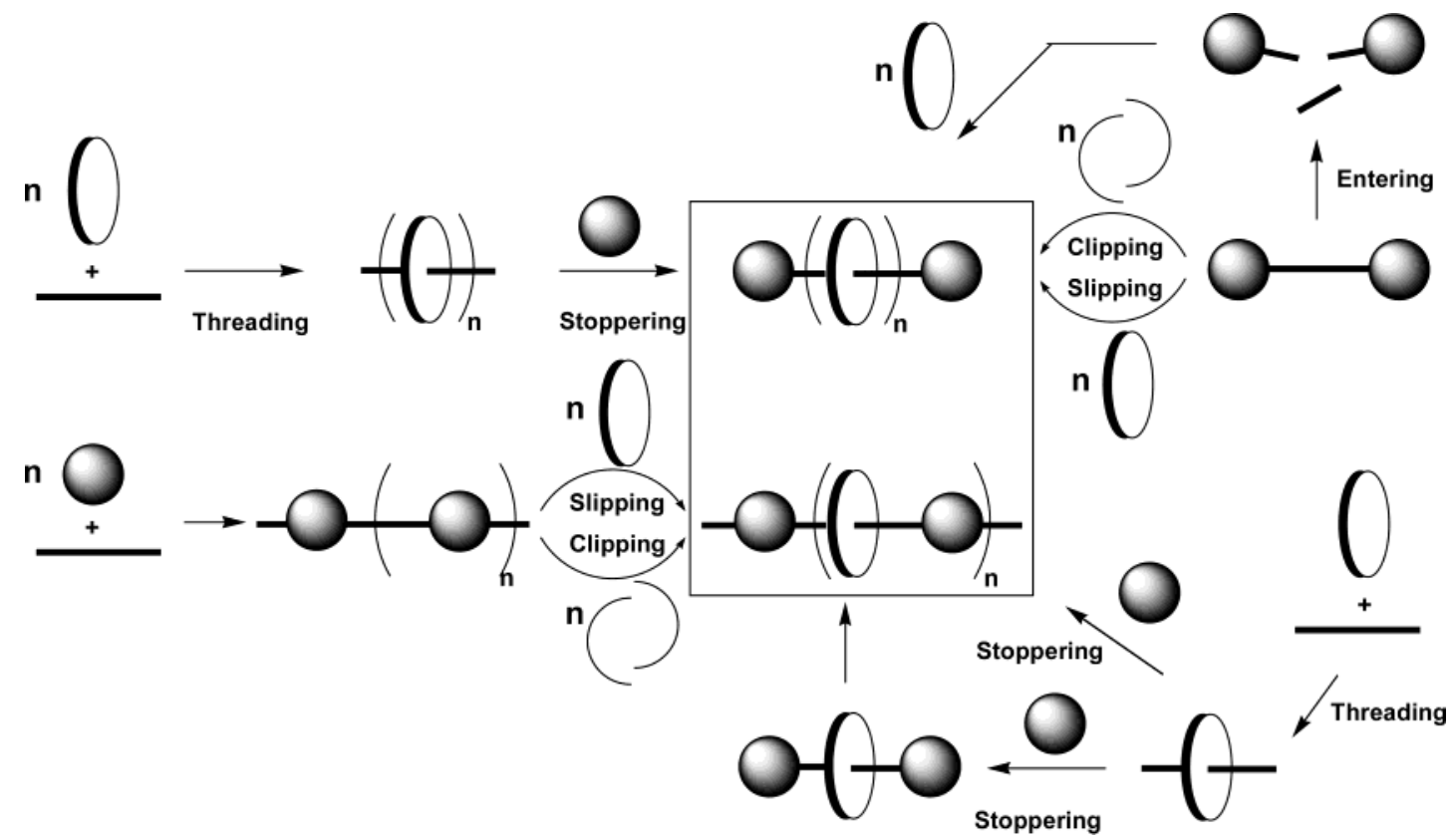

Figure 2. Generic routes for the synthesis of main chain polyrotaxanes.

the macrocycle to be threaded onto the polymer chain is crucial for successful slippage. ${ }^{71-74}$ Recently, polyrotaxanes have been obtained whereby the process of slipping combines polymerization with simultaneous threading using difunctional monomers. ${ }^{75}$ The fifth strategy for the synthesis of main chain polyrotaxanes is entering. This approach relies on a polymer backbone that can be reversibly disassembled, with macrocycles becoming incorporated during the reassembly process (Figure 2). ${ }^{76}$ In an el egant synthesis Takata et al. have demonstrated the validity of this concept by employing the $\mathrm{pH}$ dependence of disulfide/thiol scrambling equilibria in the formation of poly[3]rotaxanes. ${ }^{77}$

None of the five strategies provide complete control over the number of macrocycles threaded. An exception is the polymerization of preformed rotaxane monomers, which is synthetically demanding ${ }^{1}$ and positions each macrocycle within a narrowly defined space, thereby reducing the benefits of unusual behavior that arise from the interdependent polymer chain/macrocycle dynamics and their individual chemical characteristics.

Our motivation was to investigate a novel synthetic approach that may allow us to achieve ul timate control of threading without having to resort to preformed rotaxane monomers. 1,16-19,21,60 Key to our methodol ogy is a chemically and thermally exceptionally robust macrocycle that has been in scientific hibernation since its first synthesis by Behrend et al. in 1905.78 The seminal work by Mock et al. ${ }^{79-89}$ in the 1980s brought this unusual molecule, to which the name of cucurbituril (now cucurbit[6]uril) was given in analogy to its shape being reminiscent of that of a gourd or pumpkin (Figure $3)$, to the attention of the supramolecular chemistry community. ${ }^{90-107}$

Cucurbit[6]uril possesses a unique set of molecular recognition modes as a consequence of its rigid, nonadecacyclic shape, hydrophobic interior, and two hydrophilic oculi formed by a set of six equidistant carbonyl groups, each set aiming at a common focal point located approximately $10 \AA$ away from the macrocycle's center of gravity. ${ }^{89,93}$ The opening of each portal is close to $4 \AA$ in diameter through which small molecules can enter the interior. ${ }^{80,83,108}$ Modifications al ong the equatorial

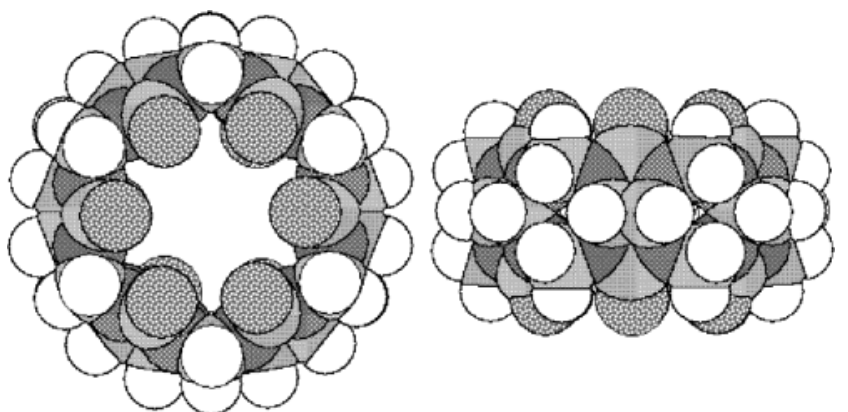

Figure 3. Space-filling representations of cucurbituril $\mathbf{1}$

perimeter of cucurbit[6]uril have rendered it soluble in organic solvents. ${ }^{109,110}$ Larger members of the cucurbituril family have been explored as new hosts for supramol ecular assemblies. ${ }^{105,111-114}$ Cucurbit[6]uril itself binds strongly to a variety of main-group ${ }^{115-118}$ and transition-metal 119,120 ions and to ali phati $c^{80,83-85,121,122}$ and aromatic mono- and diammonium ions, 80,83-85,123-125 primarily through ion-dipole interactions. Although the interior is hydrophobic toward the center of the cavitand, it gradually becomes more hydrophilic toward the carbonyl groups. ${ }^{107}$ The latter are part of the cyclic urea moieties which are responsible for the highly hygroscopic nature of cucurbit[6]uril. ${ }^{97}$ The property that distinguishes cucurbit[6]uril from any of the typical macrocycles (cyclodextrins, crown ethers, cycl ophanes) is its remarkable ability to catalyze 1,3-di polar cycloadditions in a regioselective manner (Figure 4).81,86,103,106

Our idea was to extend the catalysis shown by cucurbit[6]uril to the synthesis of polyrotaxanes by a conceptually simple extension in which azide and alkyne monomers of the $A_{2}$ and $B_{2}$ types replace those chosen in the original detailed catalytic studies conducted by Mock et al. ${ }^{81,86,89}$

\section{Results and Discussion}

1. First-Generation Monomers. The design of the monomers was based on the features first identified by Mock et al. $81,86,89$ The best spacing between the alkyne substituent and the ammonium ion was found to be a 


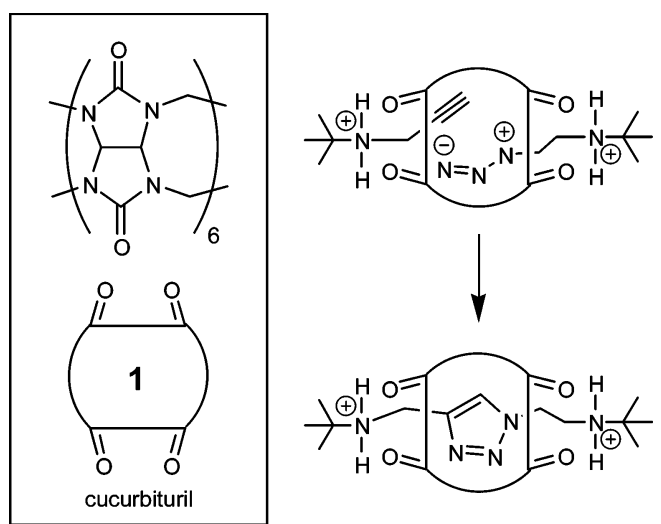

Figure 4. 1,3-Dipolar cycloaddition catalyzed by cucurbituril.
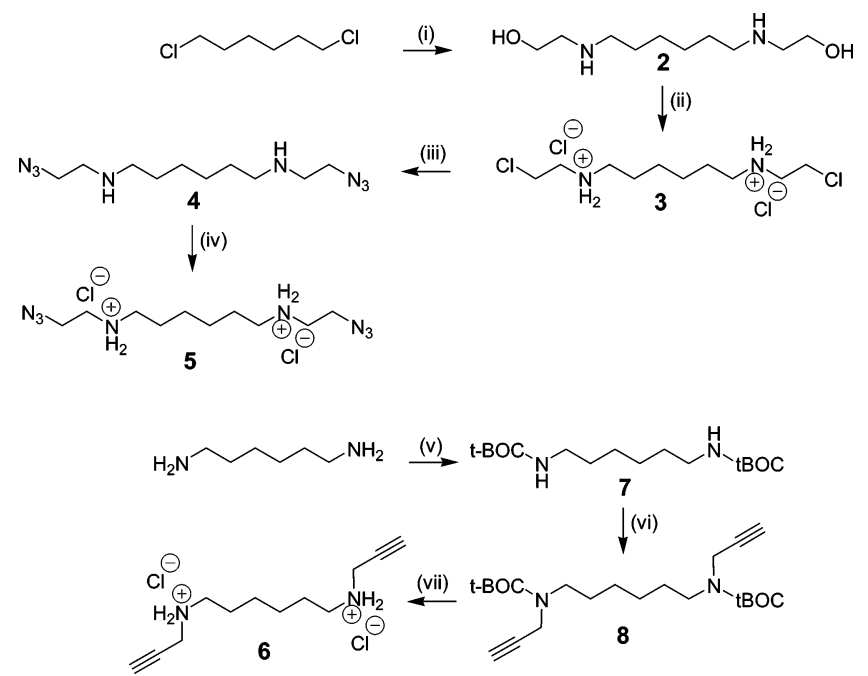

Figure 5. Synthesis of aliphatic $A_{2}$-type and $B_{2}$-type monomers 5 and $\mathbf{6}$. Conditions and reagents: (i) 2-aminoethanol (neat), $20 \mathrm{~min}$ at $120-130{ }^{\circ} \mathrm{C}$ and then $6 \mathrm{~h}$ at $150-160{ }^{\circ} \mathrm{C}$ $57 \%$; (ii) $\mathrm{SOCl}_{2}, 60^{\circ} \mathrm{C}, 100 \mathrm{~min}, 65 \%$; (iii) $\mathrm{NaN}_{3}, \mathrm{H}_{2} \mathrm{O}, 75^{\circ} \mathrm{C}$, $16 \mathrm{~h}, 60 \%$; (iv) $1 \mathrm{~N} \mathrm{HCl}$ in $\mathrm{Et}_{2} \mathrm{O}$, room temperature, 84\%; (v) $\left[\left(\mathrm{CH}_{3}\right)_{3} \mathrm{CO}_{2}\right]_{2} \mathrm{O}$, dioxane, room temperature, $48 \mathrm{~h}$; (vi) $\mathrm{BrCH}_{2-}$ $\mathrm{CCH}, \mathrm{DMF}, \mathrm{NaH}$, room temperature, $18 \mathrm{~h}$; (vii) $1 \mathrm{~N} \mathrm{HCl}$ in diethyl ether, room temperature, $4 \mathrm{~h}$.

methylene group, ${ }^{89}$ whereas for the azido substituent an ethylene spacer provides the best distance to the ammonium group. ${ }^{89}$ As the ideal spacer length to link two ammonium groups, we chose a simple hexamethylene chain because the high affinity of cucurbit[6]uril to hexamethylenediammonium ions ensures essentially $100 \%$ encapsulation of the monomer by cucurbit[6]uril. ${ }^{84}$ The final polymer structure would be a pseudopolyrotaxane in nature, which we hoped could be triggered to undergo dethreading upon a change in $\mathrm{pH}$.

We prepared monomers $\mathbf{5}$ and $\mathbf{6}$ as outlined in Figure 5. Monomer $\mathbf{5}$ was synthesized in four steps by first $\mathrm{N}$-alkylation of ethanolamine with 1,6-dichlorohexane to obtain compound $\mathbf{2}$ followed by chlorination of the hydroxy groups with $\mathrm{SOCl}_{2}$. Conversion of the resulting dichloride 3 to its hydrochloride salt form using $\mathrm{NaN}_{3}$ furnished the neutral diazido species 4, which is directly converted into its hydrochloride salt $\mathbf{5}$ obtained in $\mathbf{1 7 \%}$ overall yield. Monomer $\mathbf{6}$ was synthesized starting from 1,6-hexanediamine which was converted into its tertbutoxycarbonyl (t-BOC) protected form $7^{126}$ followed by alkylation with propargyl bromide. ${ }^{127}$ Deprotection of 8 and its conversion into the corresponding hydrochloride salt produced 6 in 36\% yield. Cucurbit[6]uril was
Table 1. Reaction Conditions for the Attempted Polymerization of Monomers 5 and 6 in the Presence of 1

\begin{tabular}{cccccccc}
\hline entry & {$[\mathbf{5}]$} & {$[\mathbf{6}]$} & {$[\mathbf{1}]$} & $\mathrm{t} / \mathrm{h}$ & $\mathrm{T} /{ }^{\circ} \mathrm{C}$ & {$[\mathbf{5}+\mathbf{6}] /[\mathrm{TrH}]$} & $\mathrm{DP}_{\mathrm{n}}{ }^{a}$ \\
\hline A & 1.00 & 1.00 & 1.00 & 24 & 20 & $16 / 0.0$ & 0.0 \\
B & 1.00 & 1.00 & 2.00 & 192 & 20 & $16 / 0.0$ & 0.0 \\
C & 1.00 & 1.00 & 3.00 & 120 & 20 & $16 / 0.0$ & 0.0 \\
D & 1.00 & 1.00 & 2.00 & 384 & 90 & $16 / 1.0$ & 1.0 \\
E & 1.00 & 1.00 & 3.00 & 384 & 90 & $16 / 0.8$ & 0.9 \\
F & 1.00 & 1.00 & 4.00 & 384 & 90 & $16 / 0.7$ & 0.8 \\
G & 1.00 & 1.00 & 0 & 384 & 90 & $16 / 0.8$ & 0.9
\end{tabular}

${ }^{a} D_{\mathrm{n}}=$ degree of polymerization defined by the ratio of the integral for the sum of both encapsulated $(0.75$ and $0.45 \mathrm{ppm})$ and free $\beta$ - and $\gamma$-methylene (1.65 and $1.35 \mathrm{ppm}$ ) protons of each monomer $(\mathbf{5}+\mathbf{6})$ divided by the integral for the triazole proton $\left(\mathrm{H}_{\mathrm{Tr}}, 8.55 \mathrm{ppm}\right)$.
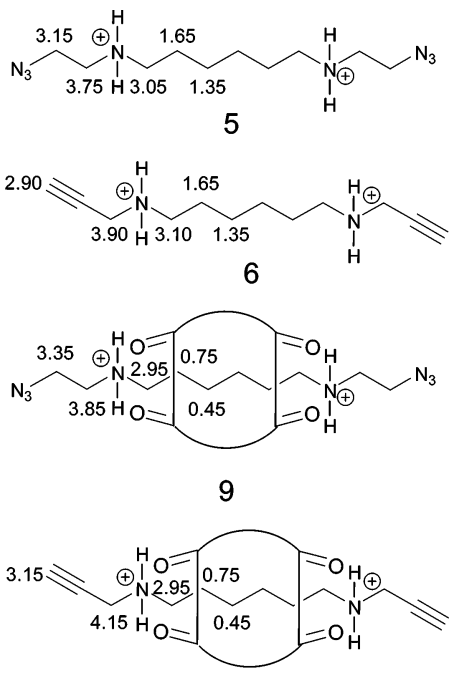

10

Figure 6. ${ }^{1} \mathrm{H}$ NMR chemical shift assignment for monomers $\mathbf{5}$ and $\mathbf{6}$ and [2]pseudorotaxanes $\mathbf{9}$ and $\mathbf{1 0}$.

synthesized according to the procedure by Behrend et al. with minor modifications. ${ }^{78}$

2. Polymerization of First-Generation Monomers. Polymerization of monomers $\mathbf{5}$ and $\mathbf{6}$ in the presence of cucurbit[6]uril was then attempted by dissolving the cavitand in $6 \mathrm{~N} \mathrm{HCl}$ (2 equiv) before 5 (1 equiv) and $\mathbf{6}$ (1 equiv) were added. After 8 days at room temperature, using the conditions we had established prior to the polymerization for the rotaxane formation (Table 1, entry B), the ${ }^{1} \mathrm{H}$ NMR spectrum of the crude product mixture only showed signals corresponding to [2]pseudorotaxanes $\mathbf{9}$ and $\mathbf{1 0}$ derived from monomers 5 and 6 encapsulated by cucurbit[6]uril (Figure 6). The ${ }^{1} \mathrm{H}$ NMR spectrum was completely devoid of any aromatic resonances, indicating the absence of any triazole protons. This was unexpected, though a possible explanation for this outcome is the slow dissociation rate constant $\left(10^{-4} \mathrm{~s}^{-1}\right)^{83}$ in conjunction with the large complexation constant $K_{\text {ass }}$ between cucurbit[6]uril and monomers $\mathbf{5}$ and $\mathbf{6}$, respectively, of approximately $10^{6-} 10^{7} \mathrm{M}^{-1} .83$ These numbers translate into only minute quantities of free cucurbit[6]uril being available for catalysis. Considering that the overall rate of the cycloaddition reaction is already slow to begin with, ${ }^{86}$ it becomes clear why triazole formation has not been observed. The reaction was repeated by adding a further equivalent of cucurbit[6]uril, ensuring that excess cavitand was available (Table 1, entry C), but again no catalysis was observed. Further variations in the reaction conditions such as different stoichiom- 

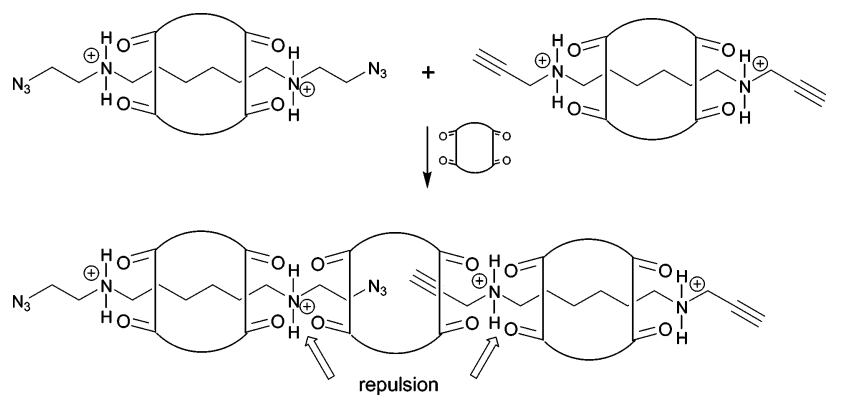

Figure 7. Suggested explanation for the suppressed catalytic activity of cucurbituril $\mathbf{1}$ in the presence of monomers $\mathbf{5}$ and 6.

etries of reactants, longer reaction times, and higher reaction temperatures were investigated but to no avail (Table 1).

Triazole formation was observed only for reactions at elevated temperatures and prolonged reaction times. The highest degree of polymerization $\left(D P_{n}\right)$ was achieved under the conditions shown in Table 1 (entry D). By comparing the integral for the central methylene protons of the monomers (free and encapsulated) with that of the triazole proton, one can calculate the $\mathrm{DP}_{\mathrm{n}}$ of this reaction, which is merely 1 . This value suggests that under the conditions explored it is not possible for more than two monomers to react together, before the reaction somehow shuts down. Thermal instability of the azide groups in monomer $A$ is likely to be one contributing factor. F urthermore, the presence of excess cucurbit[6]uril (Table 1, entries $E$ and $G$ ) could reduce the statistical chances for azido groups to encounter alkyne moieties due to encapsulation of those cucurbit[6]urils not threaded onto $\mathbf{5}$ or $\mathbf{6}$. This would explain that the same number of triazole rings was formed regardless of the monomers being heated on their own or in the presence of excess cucurbit[6]uril (Table 1, entries $E-G)$. A small but significant increase in the number of triazole rings formed when only 2 equiv of cucurbit[6]uril was present (Table 1, entry D). We rationalize this result by assuming a relative increase in the accessibility of functional groups in general together with some catalytic contribution from cucurbit[6]uril. For steric reasons though, the conformation of the ternary complex essential for catalytic activity cannot be adopted at any further stage of the reaction. This hypothesis is illustrated in Figure 7.

3. Pseudopolyrotaxane Formation via Postthreading. To test our hypothesis regarding the structural factors that were responsible for the catalytic inactivity of $\mathbf{1}$, we prepared model polymer $\mathbf{1 1}$ which contains protonated amine loci spaced very similar to those found in monomers $\mathbf{5}$ and $\mathbf{6}$ as well as the resulting triazole product. Nylon 6/6 was reduced according to a procedure by Schulz et al. ${ }^{128}$ to obtain poly(iminohexamethylene) $\mathbf{1 1}\left(\mathrm{M}_{\mathrm{n}}=20000\right.$, PDI $\left.=2.7\right)$, in $66 \%$ yield (Figure 8 ).

NMR-scale experiments were performed by dissolving 1 in $\mathrm{DCl} / \mathrm{D}_{2} \mathrm{O}(20 \% \mathrm{w} / \mathrm{w})$ first, before 11 was added. The initial threading experiment was carried out at room temperature using ratios of $\mathbf{1}$ to polymer chain repeat unit from 0.1:1 to 5:1. After 9 days at room temperature levels of threading for all stoichiometries were still below $10 \%$. Heating identical samples to $90{ }^{\circ} \mathrm{C}$ both accelerated the threading process and substantially increased the levels of threading. ${ }^{48}$ The results are summarized in Table 2.

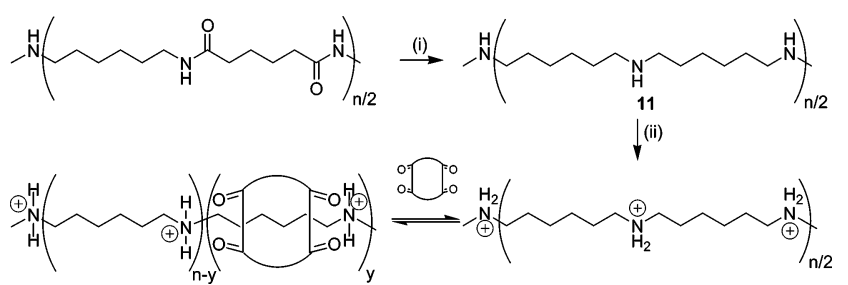

Figure 8. Synthesis of $\mathbf{1 1}$ followed by threading with cucurbituril 1. Conditions and reagents: (i) $\mathrm{BH}_{3} \cdot \mathrm{DMS}, \mathrm{THF}$, reflux, $66 \%$; (ii) $\mathrm{DCl} / \mathrm{D}_{2} \mathrm{O}(20 \% \mathrm{w} / \mathrm{w}), 20$ and $90{ }^{\circ} \mathrm{C}$.

Table 2. Reaction Conditions and the Degree of Threading for Cucurbituril 1 Threaded onto 11 in DCl/ $\mathrm{D}_{2} \mathrm{O}(20 \% \mathrm{w} / \mathrm{w})$ at 20 and $90{ }^{\circ} \mathrm{C}$

\begin{tabular}{rllllll}
\hline & \multicolumn{7}{c}{$[\mathbf{1}] /[\mathrm{n}]^{\mathrm{a}}$} \\
\cline { 2 - 7 } $\mathrm{t} / \mathrm{h}$ & $5.0 / 1$ & $1.0 / 1$ & $0.5 / 1$ & $0.3 / 1$ & $0.2 / 1$ & $0.1 / 1$ \\
\hline At $20{ }^{\circ} \mathrm{C}$ & & & & & & \\
48 & 0.02 & 0.02 & 0.05 & 0.06 & 0.05 & 0.04 \\
72 & 0.05 & 0.05 & 0.06 & 0.07 & 0.06 & 0.06 \\
216 & 0.08 & 0.07 & 0.07 & 0.08 & 0.08 & 0.06 \\
At $90{ }^{\circ} \mathrm{C}$ & & & & & & \\
48 & 0.33 & 0.23 & 0.26 & 0.22 & 0.18 & 0.10 \\
144 & 0.42 & 0.41 & 0.41 & 0.30 & 0.19 & 0.10 \\
216 & 0.47 & 0.43 & 0.44 & 0.30 & 0.20 & 0.11 \\
384 & 0.49 & 0.45 & 0.46 & 0.30 & 0.20 & 0.11 \\
456 & 0.50 & 0.45 & 0.46 & 0.30 & 0.20 & 0.10
\end{tabular}

${ }^{a}[\mathbf{1}] /[n]=$ degree of threading; $n=$ number of repeat units.
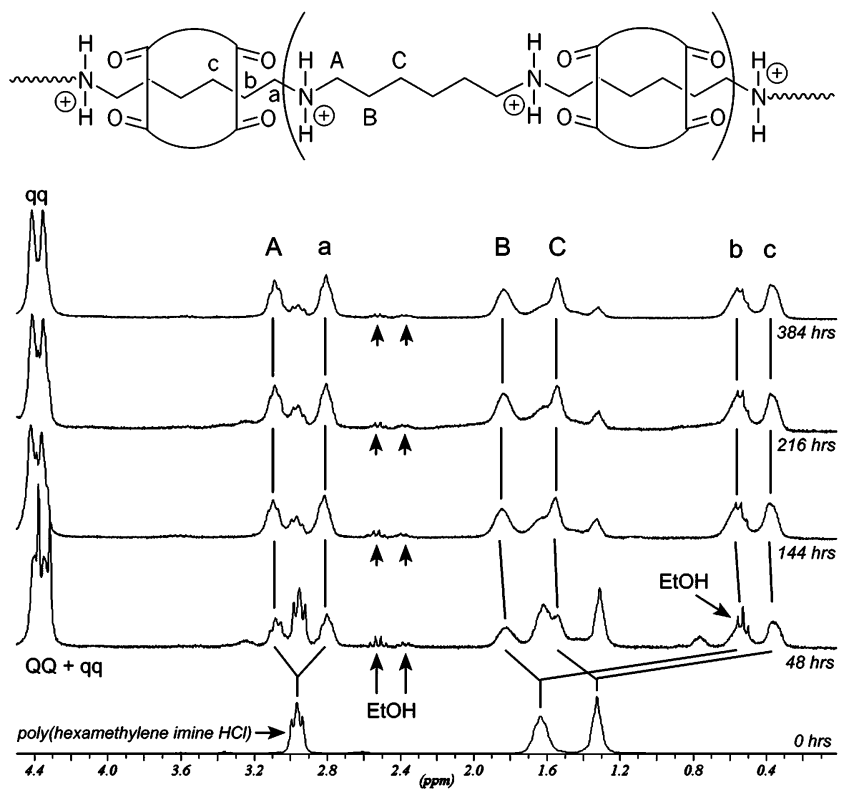

Figure 9. Time dependence of postthreading followed by ${ }^{1} \mathrm{H}$ $\mathrm{NMR}$ at $90{ }^{\circ} \mathrm{C}$ in $\mathrm{DCl} / \mathrm{D}_{2} \mathrm{O}(20 \% \mathrm{w} / \mathrm{w})$ with a molar ratio of cucurbituril to hexamethyleniminium repeat unit of 0.5:1.0. Arrows indicate traces of an ethanol inclusion complex with cucurbituril (ethanol was used as cosolvent during recrystallization) decreasing with time progressively replaced by polymer chain repeat units.

The progress of the threading reaction was monitored at given time intervals by ${ }^{1} \mathrm{H}$ NMR (Figure 9). The degree of threading is defined as the ratio of $\mathbf{1}$ per hexamethylenimi nium repeat unit. F igure 9 corresponds to a threading experiment carried out at $90^{\circ} \mathrm{C}$ in $\mathrm{DCl} / \mathrm{D}_{2} \mathrm{O}$ $(20 \% \mathrm{w} / \mathrm{w})$ with a molar ratio of cucurbit[6]uril to repeat unit of 0.5:1.0 with ${ }^{1} \mathrm{H}$ NMR spectra recorded after 48, 144, 216, and $384 \mathrm{~h}$. F or comparison the spectrum of the unthreaded polymer backbone has been included. Upon threading, the original three resonances of the $\alpha-$, $\beta$-, and $\gamma$-methylene groups of poly(iminium hexameth- 


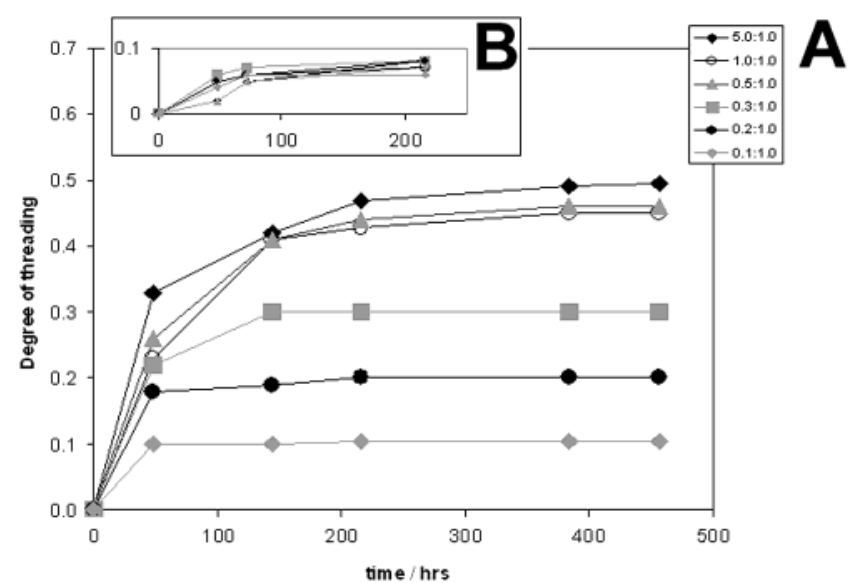

Figure 10. Time dependency of the threading of cucurbituril onto poly(iminium hexamethylene) chloride at $90{ }^{\circ} \mathrm{C}$ (graph A) and $20^{\circ} \mathrm{C}$ (graph $\mathrm{B}$, inset) in $\mathrm{DCl} / \mathrm{D}_{2} \mathrm{O}(20 \% \mathrm{w} / \mathrm{w})$. The molar ratios of cucurbituril to repeat unit used are 0.1:1.0, 0.2:1.0, 0.5:1.0, 1.0:1.0, and 5.0:1.0.

ylene) chloride are split into an additional two sets of resonances (Figure $9, A-C$ and $a-c$ ). The integrals of the new resonances increase over time to the same extent as the resonances for unthreaded hexamethylene segments decrease. Resonances coded $a-c$ have been assigned to threaded hexamethylene segments, on the basis of complexation studies of $\mathbf{1}$ with the model compound 1,6-diaminohexane dihydrochloride salt in $\mathrm{DCl} / \mathrm{D}_{2} \mathrm{O}(20 \% \mathrm{w} / \mathrm{w})$ and the data obtained from [2]pseudorotaxanes $\mathbf{9}$ and $\mathbf{1 0}$ (see Figure 6), with further support by earlier work in aqueous formic acid carried out by Mock et al. ${ }^{83}$ Resonances $\mathrm{A}-\mathrm{C}$ belong to unthreaded hexamethylene segments next to threaded repeat units al ong the polymer backbone. A downfield shift is experienced by all protons likely due to the proximity of the magnetically anisotropic carbonyl groups of $\mathbf{1}$. The assignments were confirmed by repeating the same threading experiment with a 5-fold excess of cucurbit[6]uril since under these conditions essentially all precursor resonances disappeared and only two new sets of resonances $(A-C$ and $a-C)$ remained. ${ }^{1} \mathrm{H}$ NMR data from the threading of 1 equiv of cucurbit[6]uril onto bis(6-aminohexyl)amine trihydrochloride are also consistent with this interpretation.

The degree of threading was calculated from the ratio of threaded to nonthreaded methylene protons and was cross-checked by comparing the ratio of threaded methylene protons to cucurbit[6]uril protons. In the example shown (Figure 9) $46 \%$ of all repeat units were threaded by cucurbit[6]uril after $384 \mathrm{~h}$. Threading is also indicated by a small downfield shift in the resonances of cucurbit[6]uril (Figure 9, QQ, free 1; qq, threaded 1), also proportional to the degree of threading. Figure 10 illustrates the very slow kinetics of the threading process at $20^{\circ} \mathrm{C}$ (inset B) and $90^{\circ} \mathrm{C}$. The data suggest that the system is only close to equilibrium after heating for almost $400 \mathrm{~h}$ at $90{ }^{\circ} \mathrm{C}$ for all ratios of cucurbit[6]uril to polymer repeat unit investigated. In the presence of 0.1 or 0.2 equiv of 1 per repeat unit the final degree of threading is very cl ose to the theoretical maximum given the experimental margin of error of $1-2 \%$. At a ratio of $0.5: 1$ the degree of threading reaches a value of $46 \%$, close to but significantly below the theoretical limit. A supply of equimolar amounts of cucurbit[6]uril had little impact on the maximum degree of threading, though by using a 5-fold excess of $\mathbf{1}$ our data suggest that a degree of threading of essentially $50 \%$ was reached, suggesting the existence of an upper limit. We believe that, through the limit found for the degree of threading (50\%) and the clear splitting of the original ${ }^{1} \mathrm{H} N M R$ signals of the hexamethyleniminium repeat units into two new sets of peaks of equal intensity, this can best be rationalized on symmetry grounds by invoking the formation of a pseudopolyrotaxane with alternating encapsulated and uncomplexed repeat units. Further evidence to this effect was provided by encapsulation studies between cucurbit[6]uril and bis(6-aminohexyl)amine trihydrochloride, the triamine being used as a "dimer" model for the polymer backbone. A 2-fold excess of cucurbit[6]uril led to $45 \%$ encapsulated hexamethyl eniminium segments, a value close to that found for the threaded polymer. Other substructures were also considered, in a vein similar to that of recent ${ }^{1} \mathrm{H}$ NMR investigations by Hodge et al., 50 though we have concluded that an alternating sequence of threaded and nonthreaded repeat units is most consistent with our experimental data.

Intriguingly, at the maximum level of threading of $30 \%$ for a ratio of 0.3:1 (Table 2, Figure 10 ), the ${ }^{1} \mathrm{H}$ NMR spectra showed three resonances of almost equal intensity corresponding to the $\alpha$-methylene protons (in appearance somewhere between the ${ }^{1} \mathrm{H}$ NMR spectra after 48 and $144 \mathrm{~h}$ in Figure 9) as expected for a degree of threading of close to $1 / 3$. The chemical shift region (1.2$2.0 \mathrm{ppm}$ ) of the $\beta$ - and $\gamma$-methylene protons showed six overlapping resonances of similar intensity, which indicates a high level of order along the polymer backbone. In fact there are only three possible threading arrangements that can explain this observation, though unfortunately the dynamic nature of the pseudopolyrotaxane and the general level of peak broadening have made it impossible so far to distinguish between them.

The slow threading kinetics overall can be explained through a combination of factors. By far the most important contribution arises from the strong association constant of cucurbit[6]uril to the protonated hexamethylene-spaced repeat unit in combination with a slow dissociation rate constant as has been shown for a model repeat unit. 83,84 Therefore, efficient "hopping" of cucurbit[6]uril al ong the polymer backbone requires a high activation energy as illustrated by the differences in threading kinetics at 20 and $90{ }^{\circ} \mathrm{C}$. F urther support for this interpretation has been provided by Harada et al., who have related sl ow threading kinetics to strong ionic interactions between the macrocycle and polymer chain. ${ }^{62}$ Similar behavior has been observed also by $\mathrm{Kim}$ et al. in the threading of cucurbit[6]uril onto oligoviologenes. ${ }^{129}$ Wenz et al. studied the postthreading of $\alpha$-CDs onto ionene-6,10 and calculated the observed threading kinetics successfully by employing a hopping mechanism as the model. ${ }^{130}$ Their pseudopolyrotaxane system also required elevated temperatures and long reaction times $\left(120 \mathrm{~h}\right.$ at $80{ }^{\circ} \mathrm{C}$ in water) to reach $50 \%$ as their highest degree of threading. Furthermore, we argue that threading kinetics in our system are further retarded by cucurbit[6]uril moieties having to queue especially toward higher threading levels. Queuing takes place in the formation of pseudopolyrotaxanes as has been demonstrated by Parsons et al. ${ }^{52,131}$ As expected the effect of queuing becomes more significant also in our system for higher levels of threading as reflected in the slowing of the threading progress with increasing time (Figure 10). 


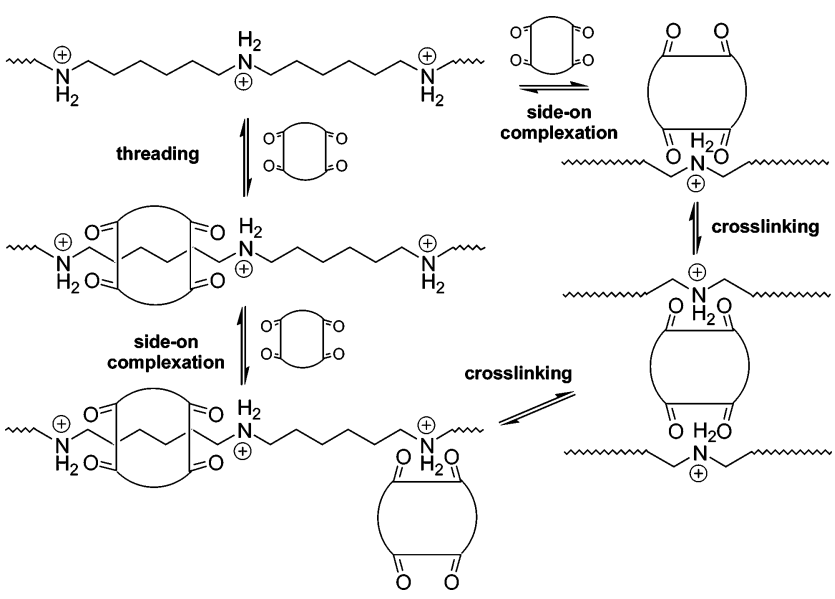

Figure 11. Dynamic equilibria that are part of the complex threading process of cucurbituril onto linear poly(iminium oligoalkylene)s.

Possessing two portals which can also bind to ammonium ions without the need for forming an inclusion complex, unthreaded cucurbit[6]uril may interfere in the hopping process through side-on complexation and formation of dynamic physical cross-links. Figure 11 is therefore a more accurate representation of the competing modes of complexation that have to be considered to describe the present system in sufficient detail. If one assumes that the kinetics of the side-on complexation are significantly faster than the $K_{\text {diss }}$ of the chain hopping, then the effect will be small. Additional experiments will be required to establish the contributions of each of these modes of complexation.

4. Second-Generation Monomers. These threading studies have given us vital information on the consequences of spacer length to the complexation behavior of cucurbit[6]uril. Clearly, the hexamethylene spacer chosen in the design of monomers $\mathbf{5}$ and $\mathbf{6}$ is too short to simultaneously allow two individual cucurbit[6]uril portals to complex to the same ammonium ion. Furthermore, the dissociation rate constant is too small to produce sufficient numbers of cucurbit[6]uril available to form ternary complexes required for catalysis. At this juncture we could investigate the effect of the alkyne and azide substrates on the kinetics of the 1,3-dipolar cycloaddition and try either to enhance its rate or, and this appeared to be a more rewarding avenue, to reduce the association rate constant between cucurbit[6]uril and each monomer, in effect the design of new monomers with a much reduced affinity toward encapsulation by cucurbit[6]uril.

The most prudent approach would be to rule out the possibility of cucurbit[6]uril threading onto any new monomer through the introduction of stopper groups. ${ }^{132}$ Once again the seminal work by Mock et al. provided us with the necessary guidance. Groups bulkier than cyclohexyl rings ${ }^{108}$ and disubstituted aromatic sixmembered rings with the exception of 1,4-disubstituted ones are not included in the interior of cucurbit[6]uril.80,83,84 We identified 2,4-bis(chloromethyl)-1,3,5trimethylbenzene (12), from which we could synthesize both the bisalkyne and the bisazido monomers (Figure 12).

$\mathrm{N}$-\{2,4,6-Trimethyl-3-[(2-propynylamino)methyl $\}$ benzyl \}-2-propyn-1-amine dihydrochloride (14) was synthesized via $\mathrm{N}$-alkylation of propargylamine to yield crude 13 in $100 \%$ yield and directly converted to its $\mathrm{HCl}$ salt in $86 \%$ overall yield. The steric demand of the ortho-

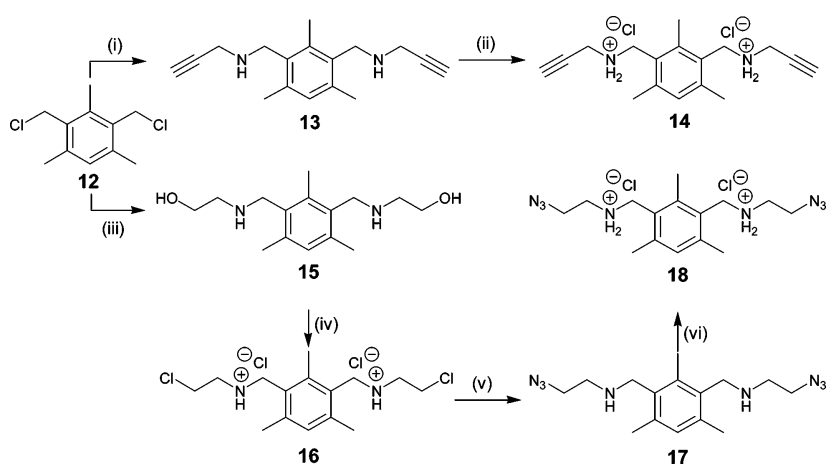

Figure 12. Synthesis of monomers 14 and $\mathbf{1 8}$. Conditions and reagents: (i) $\mathrm{NH}_{2} \mathrm{CH}_{2} \mathrm{C} \equiv \mathrm{CH}$, neat, $0^{\circ} \mathrm{C} \rightarrow$ room temperature, $16 \mathrm{~h}, 100 \%$ (crude); (ii) $1 \mathrm{~N} \mathrm{HCl}$ in $\mathrm{Et}_{2} \mathrm{O}$, room temperature, 86\%; (iii) $\mathrm{NH}_{2} \mathrm{CH}_{2} \mathrm{CH}_{2} \mathrm{OH}$, neat, $5 \mathrm{~h}, 150-160{ }^{\circ} \mathrm{C}, 66 \%$; (iv) $\mathrm{SOCl}_{2}, \mathrm{CHCl}_{3}, 5 \mathrm{~h}$, room temperature, $70 \%$; (v) $\mathrm{NaN}_{3}, \mathrm{H}_{2} \mathrm{O}$, $75{ }^{\circ} \mathrm{C}, 16 \mathrm{~h}, 87 \%$; (vi) $1 \mathrm{~N} \mathrm{HCl}$ in $\mathrm{Et}_{2} \mathrm{O}$, room temperature, $96 \%$.

positioned methyl groups on the ring was sufficient to suppress the possible second nucleophilic attack of the alkylated propargylamine toward 12. This steric "protecting-group" approach proved equally useful in the preparation of $\mathrm{N}$-(2-azi doethyl)-N-(3-\{\{ (2-azi doethyl)amino]methyl\}-2,4,6-trimethyl benzyl)amine dihydrochloride (18). Starting material 12 was alkylated first with ethanolamine, subsequently treated with thionyl chloride to yield 16, and isolated as its dihydrochloride salt. Use of excess sodium azide led to the formation of 17 sufficiently pure to prepare dihydrochloride salt $\mathbf{1 8}$ directly (39\% overall yield).

5. Polymerization of Second-Generation Monomers. With 14 and 18 in hand we repeated our initial attempts to trigger cucurbit[6]uril into catalytic activity (see Figure 7). ${ }^{132}$ In a typical polymerization $\mathbf{1}$ was dissolved in $6 \mathrm{~N} \mathrm{HCl}$ followed by addition of first 14 and then 18. For workup, each solution was precipitated into a mixture of acetone and ethanol to yield a white solid. Excess 1 was removed by dissolution of the polymer in hot water $\left(80{ }^{\circ} \mathrm{C}\right)$ followed by filtration. The final polymer was obtained as a col orless film. Polymerization conditions are summarized in Table 3.

${ }^{1} \mathrm{H}$ NMR became the most valuable and revealing tool for the structural characterization of the polymerization products. The structure of the polymer that we expected to form (19) is shown in Figure 13. The most informative proton resonances are those of the triazole proton $\left(\mathrm{H}_{\mathrm{Tr}}\right)$ and the phenyl proton $\left(\mathrm{H}_{\mathrm{Ph}}\right)$. Both resonances appear in a region of the ${ }^{1 H}$ NMR spectrum not occupied by any other species as shown in Figure 14. Our ${ }^{1} \mathrm{H}$ NMR assignments of $\mathbf{1 9}$ were ascertained through a comparison with ${ }^{1} \mathrm{H}$ NMR data of model rotaxanes. To this end [2]rotaxane $\mathbf{2 0}$ and [3] rotaxane $\mathbf{2 \mathbf { 1 } ^ { 1 0 6 }}$ were prepared by reacting stoichi ometric amounts of azide $\mathbf{2 2}$ with alkyne $\mathbf{2 3}$ or 14, respectively (Figure 15).

Figure 14 illustrates that the triazole proton is positioned at around $6.5 \mathrm{ppm}$ whereas the phenyl proton is detectable close to $7.2 \mathrm{ppm}$. The assignment of the model compounds is reflected in the resonances found for polyrotaxane 19 ( ${ }^{1} \mathrm{H}$ NMR of entry $A$ in Table 3$)$. The presence of the triazole proton in itself demonstrates that cucurbit[6]uril has acted as a catalyst joining together monomers 14 and 18 through a newly formed 1,3-disubsubtituted triazole. By taking another look at structure 19 in Figure 13, one real izes that each repeat unit of the polymer contains two triazole protons and two phenyl protons. Integration of the correspond- 
Table 3. Reaction Conditions and Molecular Weight Data for the Polymerization of Monomers 14 and 18 in the Presence of 1 Dissolved in 6 N HCla

\begin{tabular}{|c|c|c|c|c|c|c|c|c|}
\hline entry & [14]/molar equiv & [18]/molar equiv & [1] $/$ molar equiv & $\mathrm{t} / \mathrm{h}$ & $\mathrm{T} /{ }^{\circ} \mathrm{C}$ & yield/\% & $M_{n}\left({ }^{1} H N M R\right)$ & $\mathrm{DP}_{\mathrm{n}}$ \\
\hline A & 1.00 & 1.00 & 2.00 & 48 & 20 & 68 & 13000 & 5 \\
\hline B & 1.00 & 1.00 & 2.00 & 144 & 20 & 82 & 25000 & 10 \\
\hline $\bar{C}$ & 1.00 & 1.00 & 2.00 & 336 & 20 & 75 & 30000 & 11 \\
\hline $\mathrm{D}^{\mathrm{b}}$ & 1.00 & 1.00 & 2.00 & 192 & 20 & 79 & 21000 & 8 \\
\hline $\mathrm{E}$ & 1.00 & 1.00 & 2.00 & $72+24$ & $20+40$ & 75 & 28000 & 11 \\
\hline $\mathrm{F}$ & 1.00 & 1.00 & 2.00 & 120 & 60 & 68 & 39000 & 15 \\
\hline G & 1.00 & 1.00 & 2.00 & 144 & 80 & 91 & 29000 & 11 \\
\hline $\mathrm{H}$ & 1.00 & 1.00 & 2.00 & 144 & 90 & 86 & 18000 & 7 \\
\hline I & 1.00 & 1.00 & 2.00 & 336 & 90 & 79 & 25000 & 10 \\
\hline i & 1.00 & 1.00 & 2.25 & 144 & 20 & 73 & 7000 & 3 \\
\hline $\mathrm{K}$ & 1.12 & 1.00 & 2.36 & 144 & 20 & 72 & 12000 & 5 \\
\hline L & 1.20 & 1.00 & 2.48 & 144 & 20 & 71 & 12000 & 5 \\
\hline M & 1.00 & 1.00 & 2.25 & 144 & 90 & 84 & 12000 & 5 \\
\hline $\mathrm{N}$ & 1.00 & 1.00 & 1.00 & 192 & 90 & ni & 3400 & 0.5 \\
\hline 0 & 1.00 & 1.00 & 0 & 192 & 20 & 100 & na & na \\
\hline $\mathrm{P}$ & 1.00 & 1.00 & 0 & 192 & 90 & ni & 300 & 0.5 \\
\hline
\end{tabular}

${ }^{a} \mathrm{DP}_{\mathrm{n}}=$ degree of polymerization; na = not applicable; $\mathrm{ni}=$ not isolated. See the text and Figure 3 for the calculation of molar mass and $\mathrm{DP}_{\mathrm{n}}$. ${ }^{\mathrm{b}}$ Solvent: $0.2 \mathrm{M} \mathrm{Na}_{2} \mathrm{SO}_{4}$.

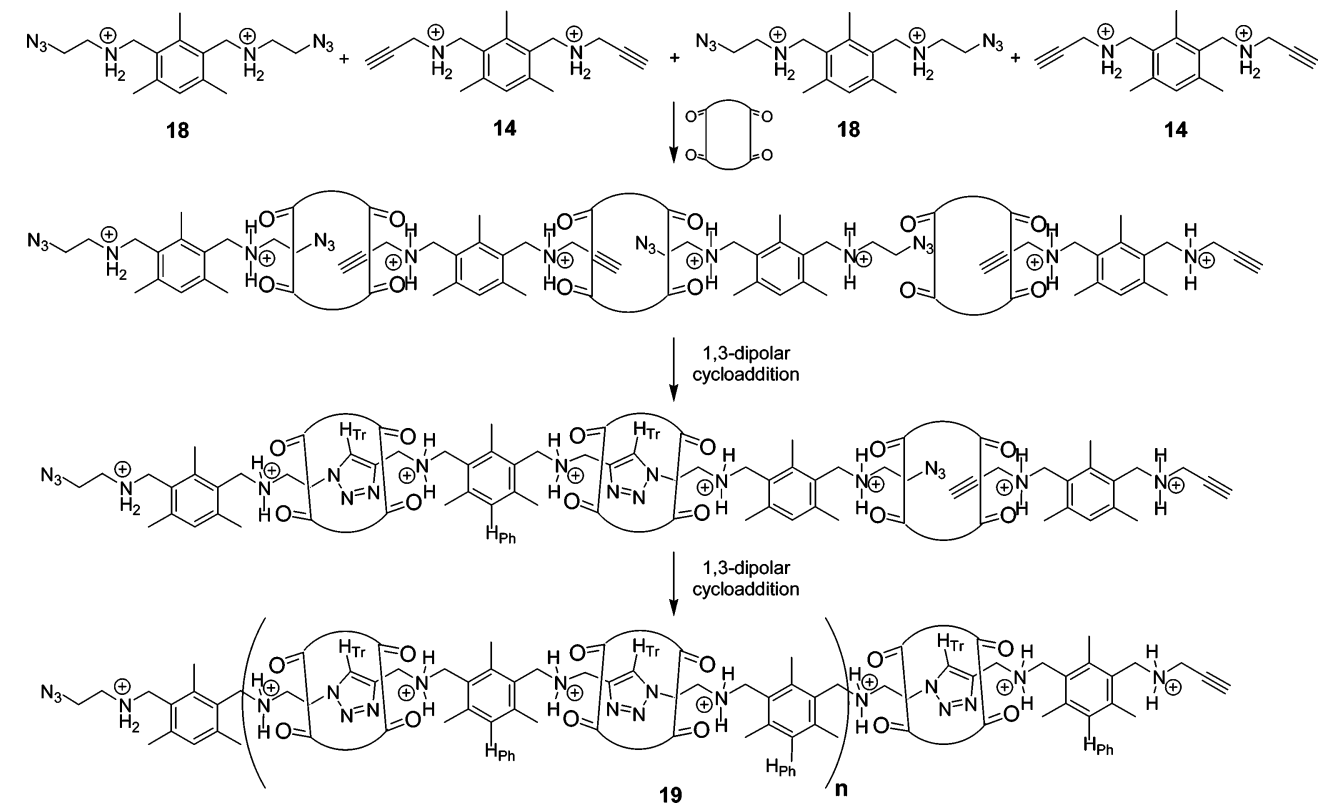

Figure 13. Synthesis of a "perfect" main chain polyrotaxane (19) via catalytic self-threading. See Table 3 for reaction conditions.

ing resonances in the ${ }^{1} \mathrm{H}$ NMR spectra allows us to determine the degree of polymerization according to Carothers' equation. An infinite polymer chain would have been formed when the ratio of the peak areas of integration of $\mathrm{H}_{T r}$ and $\mathrm{H}_{\mathrm{Ph}}$ was equal to 1 . In the example shown in Figure 14 the ratio was calculated to be 0.9 , which is equivalent to a degree of polymerization of 5 . With the molecular weight of a repeat unit (see Figure 13) close to 2600, the number-average molecular weight of the polymer therefore is about 13000 and the number-average degree of polymerization $\left(D P_{n}\right)$ is 10. Further evidence that the presence of cucurbit[6]uril is pivotal for polymerization to take place is found by reducing the number of equivalents of cucurbit[6]uril from 2 to 1 and by carrying out the reaction without cucurbit[6]uril all together. Equimolar amounts of monomers $\mathbf{1 4}$ and $\mathbf{1 8}$ and catalyst $\mathbf{1}$ (Table 3 , entry N) brought about the expected formation of the [2]rotaxane. In the absence of $\mathbf{1}$, monomers $\mathbf{1 4}$ and $\mathbf{1 8}$ show no sign of undergoing 1,3-dipolar cycloaddition at room temperature precedented by complete recovery of starting materials (Table 3, entry 0 ). However, cycloaddition chemistry takes place when both monomers are heated for 9 days at $90{ }^{\circ} \mathrm{C}$, in which case an average of one triazole ring is formed for every set of 14 and 18 present.

We found that increasing the polymerization time at room temperature led to an increase in the molecular weight of the polyrotaxane of up to 30000 after $336 \mathrm{~h}$ in good yields (Table 3, entries $A-C$ ). Entries $E-I$ in Table 3 show the effect of an increase in temperature on the number-average molecular weight. The data suggest an optimum is found at $60^{\circ} \mathrm{C}$ for 5 days (Table 3 , entry F). Longer heating periods and higher temperatures led to substantially lower mol ecular weights. We suspect the polymerization to be very sensitive toward changes in reaction conditions, in particular temperature. A possible explanation for this behavior could be the very crowded nature of the polymer backbone that is being formed, hypothesizing that the catalytic selfthreading process is reversible. Consequentially, a higher temperature brings the system closer to its ceiling temperature. The reason for lower molecular weights at $20^{\circ} \mathrm{C}$ instead of $60^{\circ} \mathrm{C}$ could be explained by the slow rate of polymerization that has not all owed us to reach equilibrium conditions within the polymerization time intervals studied. 
Table 4. Reaction Conditions and Molecular Weight Data for the Attempted Polymerization of Monomers 6 and 14 in the Presence of 1 Dissolved in 6 N HCla

\begin{tabular}{|c|c|c|c|c|c|c|c|c|}
\hline entry & [6]/molar equiv & [14]/molar equiv & [1]/molar equiv & $\mathrm{t} / \mathrm{h}$ & $\mathrm{T} /{ }^{\circ} \mathrm{C}$ & yield/\% & $M_{n}\left({ }^{1} H N M R\right)$ & $D P_{n}$ \\
\hline$A$ & 1.00 & 1.00 & 1.00 & 168 & 20 & 100 & monomers & 0 \\
\hline $\mathrm{B}$ & 1.00 & 1.00 & 2.00 & 168 & 20 & 75 & dimer & 0.5 \\
\hline $\mathrm{C}$ & 1.00 & 1.00 & 3.00 & 168 & 20 & ni & monomers & 0 \\
\hline $\mathrm{D}$ & 1.00 & 1.00 & 3.00 & 552 & 20 & 93 & $30 \%$ dimer & 0.2 \\
\hline $\mathrm{E}$ & 1.00 & 1.00 & 3.00 & 192 & 60 & 80 & dimer & 0.5 \\
\hline
\end{tabular}

${ }^{a} \mathrm{DP}_{\mathrm{n}}=$ degree of polymerization; $\mathrm{ni}=$ not isolated.

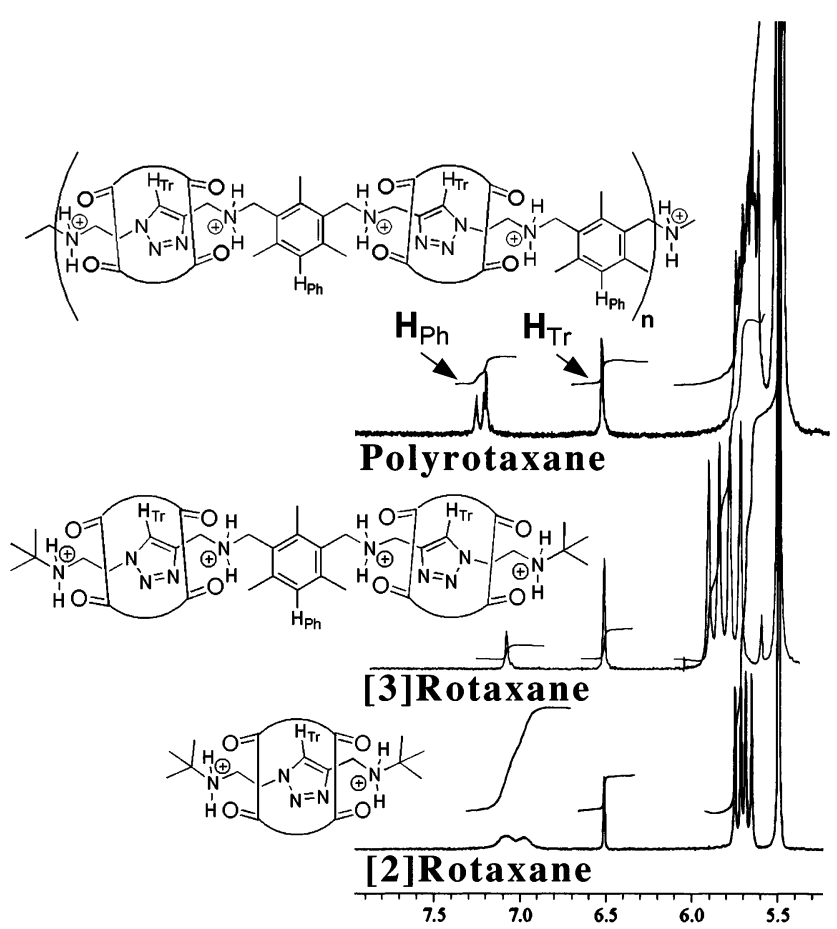

Figure 14. ${ }^{1} \mathrm{H}$ NMR overlay of the triazole and phenyl proton regions of polyrotaxane $\mathbf{1 9}$ (Table 3 , entry A) and model compounds [2]rotaxane $\mathbf{2 0}$ and [3]rotaxane $\mathbf{2 1}$.

Some additional evidence can be extracted from another set of experiments (Table 3 , entries $\mathrm{J}-\mathrm{N}$ ) designed to investigate the influence of polymerization stoichiometry. A reduction in the number-average molecular weight by $50 \%$ was found when one of the monomers was used in subequimolar amounts (Table 3 , entries $K$ and $L$ ), thereby upsetting the required stoichiometric proportions. This is the trend one would expect from a step-growth polymerization process. More interestingly though, we also found that by using 2.25 equiv instead of 2.00 equiv of $\mathbf{1}$ that $M_{n}$ of the polyrotaxane was reduced by a factor of almost 4 from 25000 to 7000 at room temperature (Table 3, entries B and J ) and to $2 / 3$ of the value from 18000 to 12000 at $90{ }^{\circ} \mathrm{C}$ (Table 3, entries $\mathrm{H}$ and $\mathrm{M}$ ). If cucurbit[6]uril is only taking part in this polymerization as a catalyst, then excess amounts of it should not affect the degree of polymerization. Excess $\mathbf{1}$ may slow the process, though even at $90{ }^{\circ} \mathrm{C}$ an excess of cucurbit[6]uril results in reduction of the mol ecular weight from 18000 to 12000 (Table 3, entries $\mathrm{H}$ and $\mathrm{M}$ ). The question arises of whether an excess of cucurbit[6]uril could be responsible for shifting the polymerization equilibrium. At present, our data suggest that such a possibility exists, but we have insufficient data to draw any firm conclusion.

Further characterization of the polyrotaxanes was carried out employing MALDI-TOF mass spectrometry. Obtaining satisfactory spectra was only met with limited success as depicted in Figure 16. The appearance of all spectra was characterized by a wide range of molar masses shaped into broad "humps" with little analytical value. MALDI-TOF spectra of polyrotaxane 19 at the high end of the molecular weight scale (Table 3, entries $C$ and $E-G$ ) did not differ substantially from the spectrum shown. A little comfort can be derived from the spacing of those clusters though, as they correspond to a molecular weight of $\sim 1350$, the approximate value for a cucurbit[6]uril-threaded segment of the polymer backbone. We also attempted to carry out gel permeation chromatography on these polyrotaxanes. To render 19 soluble in a polar organic solvent such as DMF, we exchanged the chloride counterions for hexafluorophosphate in water, which indeed provided us with homogeneous solutions in DMF, DMSO, and DMAc. GPC in DMF at $80^{\circ} \mathrm{C}$ proved disappointing since we were not able to establish satisfactory chromatographic conditions to suppress undesirable interactions of the polyrotaxane with the column material. At this point further optimization of the eluent is necessary to obtain meaningful data, which once identified will also be used to isolate fractionated polymer samples to facilitate MALDI-TOF analysis. 133,134 The chemical character of polyrotaxane $\mathbf{1 9}$ is certainly different from that of cucurbit[6]uril before and after counterion exchange. All polyrotaxanes isolated before counterion exchange were soluble in water, in which $\mathbf{1}$ is not. ${ }^{89} \mathrm{~A}$ solvent other than water "doped" with high levels of protons or alkali-metal ion salts has so far not been identified for cucurbit[6]uril.

With our success in triggering cucurbit[6]uril to catalyze the cycloadditi on between monomers which act as stopper groups, we had an opportunity to unravel the polymerization mechanism further by studying the catalytic behavior of $\mathbf{1}$ in the presence of a matched pair of monomers, only one of which containing a stopper group (Figure 17). Monomers 6 and 14 were reacted under a set of conditions summarized in Table 4.

The maximum reaction progress achieved was the formation of a single triazole ring for every pair of monomers. This shows how vital it was to have selected monomers which cannot be encapsulated by cucurbit[6]uril. Figure 17 is an attempt to translate our observations into a mechanistic scheme. The formation of [3]semirotaxane 24 (Figure 17) in the presence of 2 equiv of 1 (Table 4 , entries $A$ and $B$ ) suggests the encapsulation of monomer $\mathbf{6}$ through $\mathbf{1}$ is the first step, being faster than the catalytic threading pathway to give 24. The fact that the unstoppered monomers 5 and 6 were completely unreactive under almost identical conditions supports this view (Table 1 , entry B). A third equivalent of cucurbit[6]uril is therefore required to complex to monomer $\mathbf{1 4}$ and subsequently to form the catalytically active ternary complex, which is only possible because the first equivalent of cucurbit[6]uril encapsulating monomer $\mathbf{6}$ can slip to the right or unthread completely. Using a $50 \%$ excess of cucurbit[6]uril (Table 4, entry C), catalysis has been suppressed 


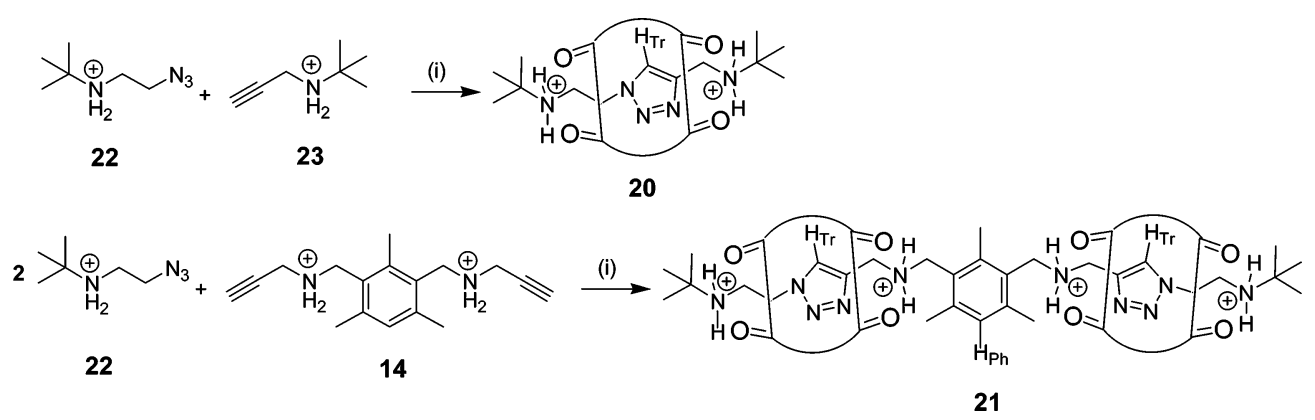

Figure 15. Synthesis of model [2]- and [3]rotaxanes $\mathbf{2 0}$ and $\mathbf{2 1}$. Conditions and reagents: (i) $\mathbf{1}, 6 \mathrm{~N} \mathrm{HCl}, \mathbf{7 2} \mathrm{h}, \mathrm{room}$ temperature, $71 \%$ (20) and $88 \%(21)$.

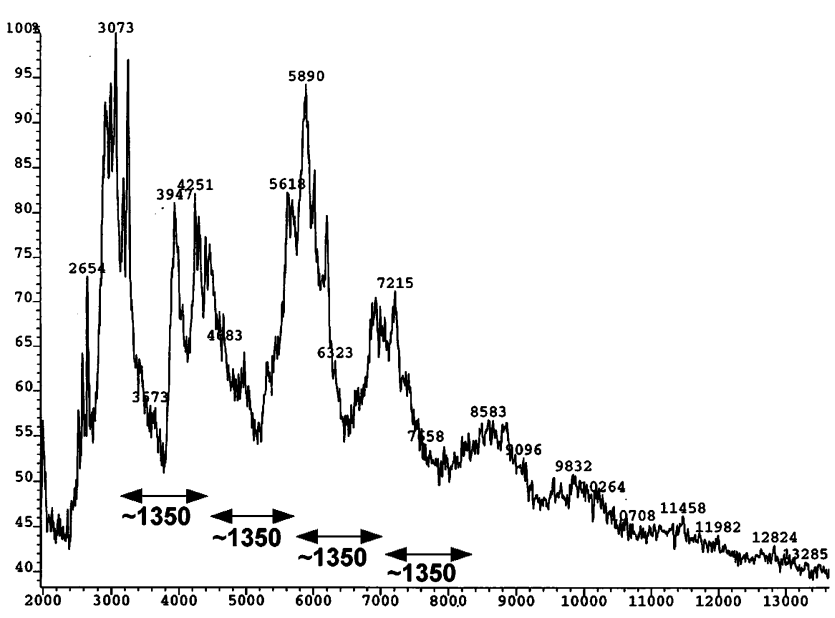

Figure 16. A representative MALDI-TOF mass spectrum for polyrotaxane 19 (Table 3, entry A).

by shifting the equilibrium of threaded to unthreaded monomer 6 strongly to the side of the former, thus significantly reducing the statistical change for the formation of the catalytic ensemble. This reading of the data is in line with entries $D$ and $E$ (Table 4), indicating that longer reaction times or elevated temperatures counteract the shift in equilibrium caused by the presence of an excess of $\mathbf{1}$.

6. Branched Polyrotaxanes. Encouraged by our ability to produce catalytically self-threading mainchain polyrotaxanes, we investigated the possibility of extending our architectural repertoire to branched analogues. For simplicity we opted for an $A_{2} / B_{3}$ system. ${ }^{135,136}$ The $A_{2}$ component was al ready in hand in the guise of 18. Since 2,4,6-tris(bromomethyl)mesitylene is commercially available, we prepared the $\mathrm{B}_{3}$ monomer 25 responsible for the branching analogously to the synthesis of 14. N-\{2,4,6-Trimethyl-3,5-bis[(2-propynylamino)methyl ]benzyl \}-2-propyn-1-amine trihydrochloride (25) was obtained in $88 \%$ yield. Polymerizations were carried out using different ratios of $\mathbf{1}, \mathbf{1 8}$, and 25 as shown in Table 5, with the structure of the expected branched polyrotaxane 26 illustrated in Figure 18.

The degree of polymerization for branched polyrotaxane $\mathbf{2 6}$ was determined by comparing the integral of the triazole proton to that of the phenyl proton in the same way as al ready described in detail for the linear mainchain polyrotaxanes. The same problems were encountered as for the linear analogues when attempts were made to obtain molecular weight information through MALDI-TOF mass spectrometry and GPC. Figure 19 shows a representative MALDI-TOF spectrum (for Table 5, entry B) with features similar to those discussed earlier. The most striking patterns are once
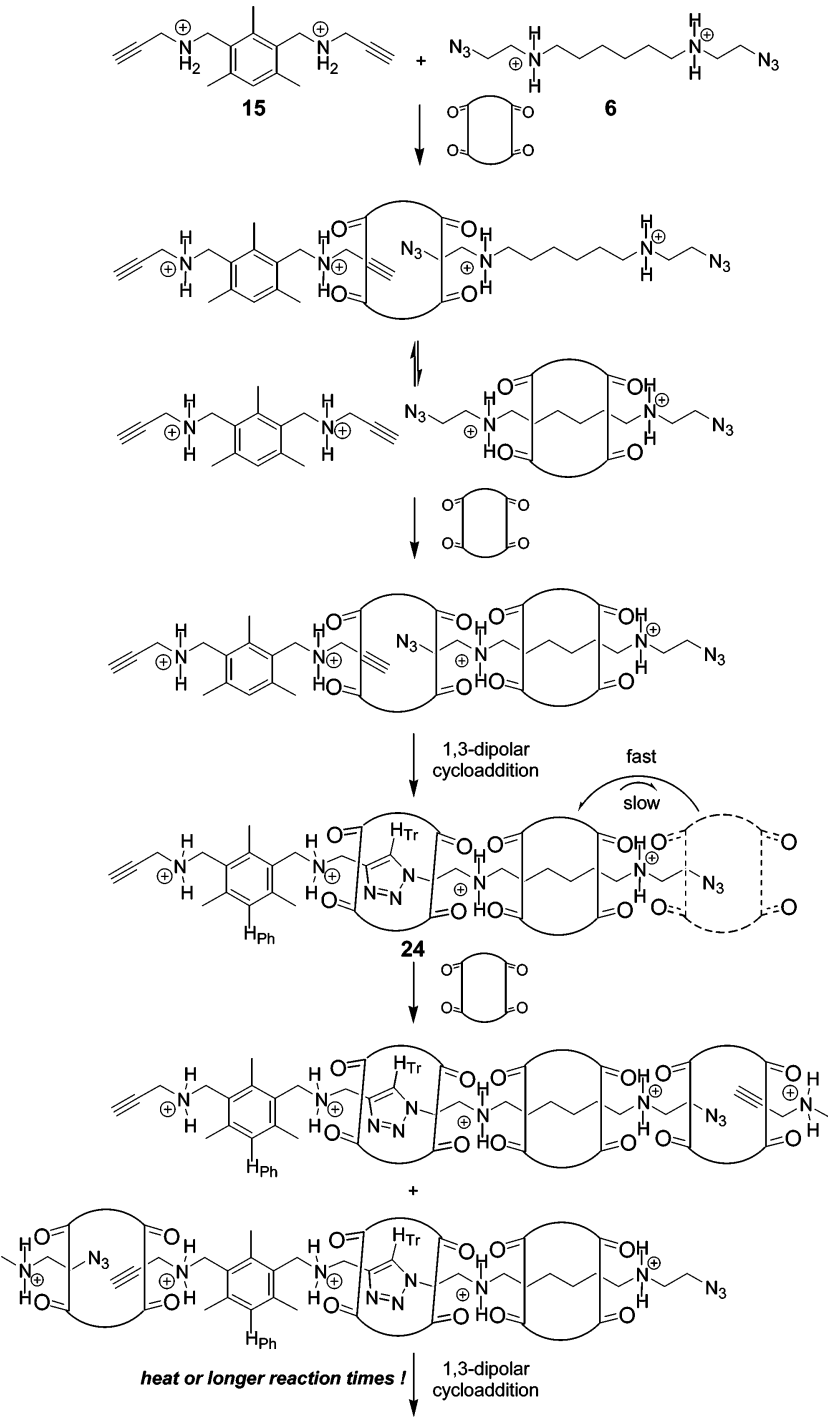

Figure 17. Formation of [3]semirotaxane $\mathbf{2 4}$ and attempted polymerization of monomers $\mathbf{6}$ and $\mathbf{1 4}$ in the presence of $\mathbf{1}$. See Table 4 for reaction conditions.

again a wide mass range of molecular ions and the separation of the clusters corresponding approximately to the molar mass of half a threaded repeat unit. ${ }^{1} \mathrm{H}$ and ${ }^{13} \mathrm{C}$ NMR analysis is the obvious tool to determine the degree of branching of polyrotaxane 26. In our attempts to quantitatively analyze these spectra, we encountered broad, and most of the time featureless, resonances, an unsurprising consequence of the polymeric nature of the molecules as well as the restricted motions of the macrocyclic cavitand. This made it essentially impossible to integrate and assign reso- 
Table 5. Reaction Conditions and Molecular Weight Data for the Polymerization of Monomers 18 and 25 in the Presence of 1 Dissolved in $6 \mathrm{~N} \mathrm{HCl}$

\begin{tabular}{ccccccrrr}
\hline entry & {$[\mathbf{1 8}] /$ molar equiv } & {$[\mathbf{2 5}] /$ molar equiv } & {$[\mathbf{1}] /$ molar equiv } & t/h & $\mathrm{T} /{ }^{\circ} \mathrm{C}$ & yield/\% & $\mathrm{M}_{\mathrm{n}}\left({ }^{1} \mathrm{H} \mathrm{NMR}\right)$ & $\mathrm{DP} \mathrm{n}{ }^{a}$ \\
\hline A & 1.00 & 1.00 & 2.00 & $96+24$ & $20+60$ & 80 & 5000 \\
B & 1.50 & 1.00 & 3.00 & 72 & 20 & 70 & 22000 \\
C & 1.50 & 1.00 & 3.00 & 96 & 20 & 75 & 32000 \\
D & 1.00 & 1.00 & 3.00 & 144 & 60 & 78 & 34000 & 13 \\
\end{tabular}

${ }^{a} \mathrm{DP}_{\mathrm{n}}=$ degree of polymerization.

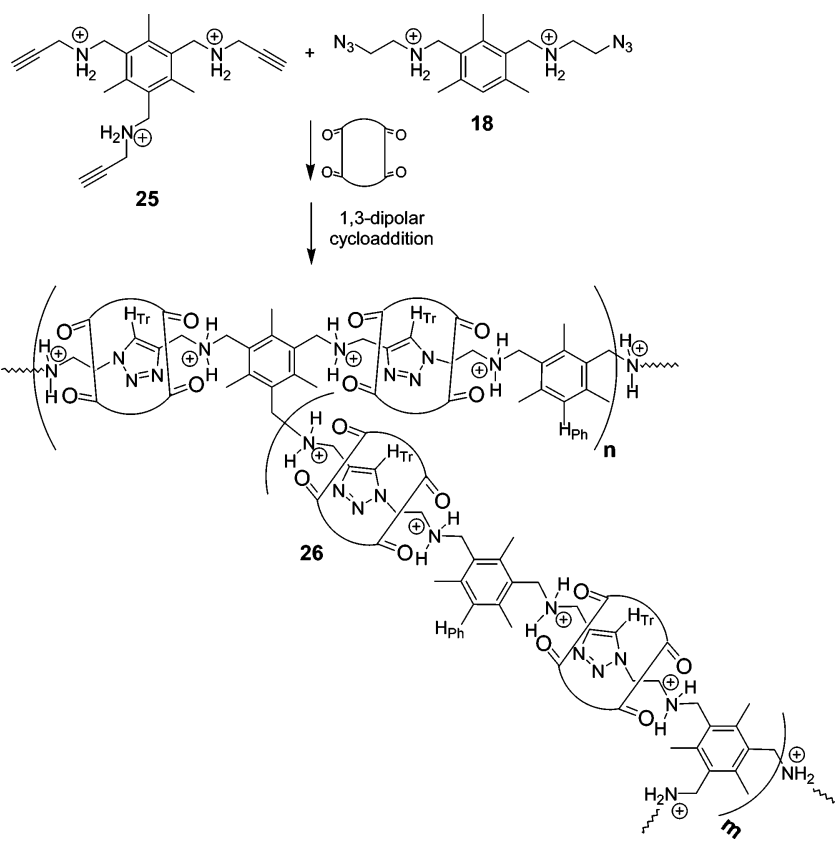

Figure 18. Synthesis of branched/hyperbranched polyrotaxane $\mathbf{2 6}$ via catalytic self-threading. See Table 5 for reaction conditions. Conditions and reagents for the synthesis of $\mathbf{2 5}$ : (i) propargylamine (neat), $0^{\circ} \mathrm{C} \rightarrow$ room temperature, $60^{\circ} \mathrm{C}$, $16 \mathrm{~h}, 100 \%$ (crude); (ii) $1 \mathrm{~N} \mathrm{HCl}$, in $\mathrm{Et}_{2} \mathrm{O}$, room temperature, $88 \%$.

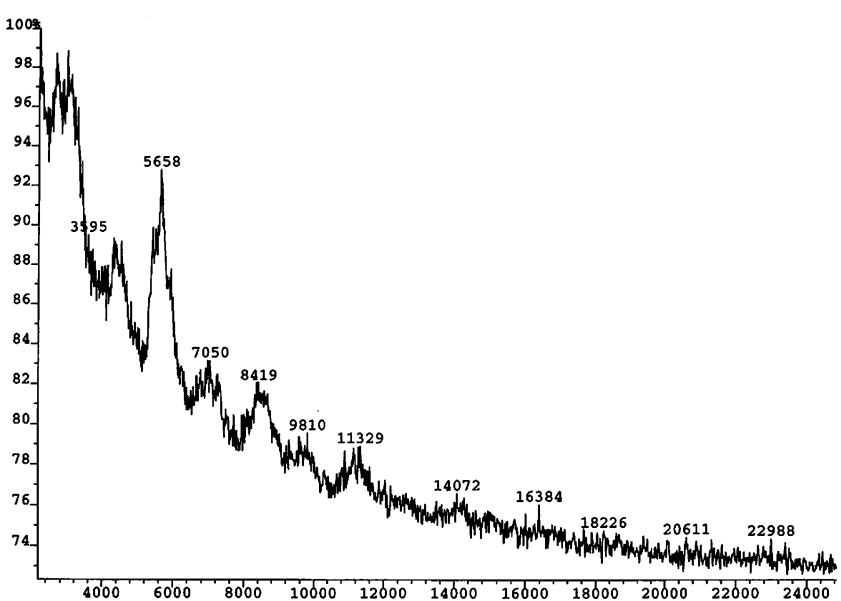

Figure 19. A representative MALDI-TOF mass spectrum for polyrotaxane $\mathbf{2 6}$ (Table 5, entry B).

nances reliably. F urthermore, the probably most promising approach to calculate the degree of branching, via end group analysis of unreacted al kyne and azide groups in conjunction with the corresponding benzyl resonances of monomer $\mathbf{2 5}$, suffered from overlapping signals such as the benzyl resonances of $\mathbf{1 8}$.

\section{Conclusions}

Catalytic self-threading has been established as a new route for the synthesis of polyrotaxanes. Investigations into the polymerization mechanism have brought to light that the catalyst cucurbit[6]uril is highly sensitive toward monomer structure, with a poorly designed monomer resulting in complete inactivity. By using monomers which contain stopper groups to prevent cucurbit[6]uril from becoming deactivated through threading, we were able to prepare main chain polyrotaxanes in high yields with molecular weights up to 39000 . These polyrotaxanes are structurally perfect in the sense that exactly two cucurbit[6]uril molecules are threaded onto each structural repeat unit, though still at the cost of restricting severely the movements of the macrocycle along the polymer backbone. The concept was extended to the synthesis of branched polyrotaxanes, though more detailed structural analysis is necessary to establish the degree of branching for these polymers.

\section{Experimental Section}

All manipulations of air- and moisture-sensitive compounds were performed under an atmosphere of nitrogen. NMR solvents were obtained commercially and used as received unless stated otherwise: $d_{4}$-methanol (Aldrich Chemicals), $d_{6^{-}}$ DMSO (Aldrich Chemicals), $d_{2}$-water (Apollo Scientific), $d_{2^{-}}$ sulfuric acid (Apollo Scientific), DCl (35\% aqueous solution $(w / w))$ (Aldrich Chemicals), and DCI (20\% aqueous solution (w/w)) (Apollo Scientific).

Solvents were dried by prolonged reflux over a suitable drying agent (in parentheses). They were distilled and degassed prior to use: tetrahydrofuran (sodium metal and benzophenone), dichloromethane (calcium hydride), diethyl ether (lithium aluminum hydride), ethanol (4 $\AA$ molecular sieves), chloroform $\left(\mathrm{P}_{2} \mathrm{O}_{5}\right)$. Reagents were obtained commercially at the highest purity available and were used as received unless stated otherwise: 1,6-diaminohexane, 1,6dichlorohexane, ethanolamine, nylon 6/6, glycoluril, propargylamine, propargyl bromide (in toluene), tert-butyl amine, 2-(N-tert-butylamino)ethanol, and 2,4,6-tris(bromomethyl)mesitylene (Aldrich Chemicals), thionyl chloride (Fluka), sodium azide (Avocado), 2,4-bis(chloromethyl)-1,3,5-trimethylenebenzene (L ancaster).

$\mathrm{N}^{1}, \mathrm{~N}^{6}-\mathrm{Bis}\left(2\right.$-hydroxyethyl)-1,6-hexanediamine ${ }^{137}(2), \mathrm{N}^{1}, \mathrm{~N}^{6}$ bis(2-propynyl)-1,6-hexanediamine dihydrochloride ${ }^{127}(\mathbf{6}), \mathrm{N}^{1}, \mathrm{~N}^{6}$ bis(tert-butoxycarbonyl)-1,6-hexanediamine ${ }^{126}$ (7), poly(iminohexamethylene) ${ }^{128}$ (11) (GPC $\left(\mathrm{CHCl}_{3}\right): \mathrm{M}_{\mathrm{n}}=20000, \mathrm{M}_{\mathrm{w}}=$ $\left.55000, D_{n}=202\right)$ ), $\mathrm{N}$-(tert-butyl)azi doethylamine hydrochloride $^{86,138,139}$ (22), and N-(tert-butyl)propargylamine hydrochloride $^{140}$ (23) were prepared according to published syntheses.

NMR solvents were obtained commercially and used as received unless stated otherwise. Infrared spectra were recorded on a Perkin-EImer 1710 and 1725 series FTIR spectrometer using $\mathrm{KBr}$ plates. Absorptions are abbreviated as follows: vs (very strong), s (strong), m (medium), w (weak), br (broad), sh (shoulder). NMR spectra were recorded on Bruker DRX400 (400 MHz, $\left.{ }^{1} \mathrm{H} ; 100 \mathrm{MHz},{ }^{13} \mathrm{C}\right)$ and Bruker AC250 (250 MHz, $\left.{ }^{1} \mathrm{H} ; 62.5 \mathrm{MHz},{ }^{13} \mathrm{C}\right)$ instruments.

MALDI-TOF mass spectrometry analysis was carried out by the ULIRS (University of London I ntercollegiate Research Service) on a Fisons VG TofSpec instrument using a semiautomatic probe, holding 12 samples at a time. The instrument was differentially pumped. The pressure in the analyzer region was $10^{-8}$ Torr, and the source region pressure was $10^{-7}$ Torr. 
The samples were prepared in water using a 1000-fold molar excess of the matrix (indoleacrylic acid). Typically $1 \mu \mathrm{L}$ of sample matrix mixture was deposited onto the sample position of a stainless steel target. The MALDI used a nitrogen laser at $337 \mathrm{~nm}$ (UV) with a shot frequency of $10 \mathrm{~Hz}$ and was operated at $28 \mathrm{kV}$ accelerating voltage. Typically, 100 shots were acquired and averaged to produce the spectrum.

GPC analysis in DMF was performed by RAPRA on a Polymer Laboratories GPC-210 using DMF with ammonium acetate as eluent. Col umns used were two $10 \mu \mathrm{m}$ PIgel mixed bed $B$ coumns $\left(30 \mathrm{~cm} ; 5 \times 10^{2}\right.$ to $\left.10 \times 10^{6} \mathrm{Da}\right)$, with a flow rate of $1.0 \mathrm{~mL} / \mathrm{min}$ (nominal) at $80{ }^{\circ} \mathrm{C}$. The system was calibrated with PMMA standards. GPC analysis in $\mathrm{CHCl}_{3}$ (stabilized with ethanol) as the eluent was performed by RAPRA on a Viscotek system equipped with a refractive index detector (also Viscotek). Columns used were two $10 \mu \mathrm{m}$ PIgel mixed bed $B$ columns $\left(30 \mathrm{~cm} ; 5 \times 10^{2}\right.$ to $\left.10 \times 10^{6} \mathrm{Da}\right)$ with a flow rate of $1.0 \mathrm{~mL} / \mathrm{min}$ (nominal) at $40^{\circ} \mathrm{C}$. The system was calibrated with PS standards. Elemental analyses were carried out at the Analytical Services of the University of North London.

Cucurbituril 1. Glycoluril (7.0 g, $49 \mathrm{mmol})$, formal dehyde (10.5 mL of a $37 \% \mathrm{w} / \mathrm{w}$ aqueous solution, $150 \mathrm{mmol}$ ), concentrated $\mathrm{HCl}(16 \mathrm{~mL})$, and water $(35 \mathrm{~mL})$ were placed in a roundbottom flask and heated to reflux until all solid had dissolved. A few minutes later, the reaction mixture turned cloudy and a precipitate was formed. The contents of the flask were poured into $350 \mathrm{~mL}$ of ice-cooled water, and a white powder precipitated. This was filtered off and subsequently washed with water $(10 \mathrm{~mL})$, ethanol $(10 \mathrm{~mL})$, and diethyl ether $(10 \mathrm{~mL})$. The white powder was dried in vacuo over $\mathrm{P}_{2} \mathrm{O}_{5}$ for a week to yield the precursor for $\mathbf{1}$. (Longer drying times better the results.) Yield: $5.42 \mathrm{~g}(42 \%)$.

To the well-dried solid was added carefully concentrated $\mathrm{H}_{2-}$ $\mathrm{SO}_{4}(2.2 \mathrm{~mL}$ of acid/g of solid). The mixture was heated under vigorous stirring to $110-120^{\circ} \mathrm{C}$ until all solid had dissolved. I nitially, the reaction mixture turned into a brown suspension but subsequently became a brown viscous solution. After being cooled to room temperature, the mixture was poured into ice cold water ( $22 \mathrm{~mL} / \mathrm{g}$ of starting material). A small amount of precipitate was filtered rapidly through a sintered glass funnel with suction. Thelight brown colored filtrate was heated gently to yield beige crystals of $\mathbf{1}$.

Crude 1 was dissolved in the minimum amount of formic acid/water $(1: 1(v / v))$ and heated to reflux for about $1 \mathrm{~h}$. The resulting solution was filtered hot with suction. The filtrate was allowed to cool to room temperature. Water (twice the vol ume of the filtrate) was added to yield a white powder. The white precipitate was washed with hot water, dried over $\mathrm{P}_{2} \mathrm{O}_{5}$ under vacuum for one week, and stored over $\mathrm{P}_{2} \mathrm{O}_{5}$. Yield: 1.81 g (21\%). Mp: > $300{ }^{\circ} \mathrm{C}$. IR ( $\mathrm{KBr}, \mathrm{Nujol}$ mull, $\left.\mathrm{cm}^{-1}\right): 3469$ $(\mathrm{NH}-), 2998(\mathrm{C}-\mathrm{H}), 1738(\mathrm{C}=\mathrm{O}) .{ }^{1} \mathrm{H}$ NMR $(250 \mathrm{MHz}, \mathrm{DCl})$ : $\delta 4.46\left(\mathrm{~d}, 12 \mathrm{H}\right.$, 2 $\left.\mathrm{H} \mathrm{HH}^{2}=15.6 \mathrm{~Hz}, \mathrm{H}_{\mathrm{b}}\right), 5.54\left(\mathrm{~d}, 12 \mathrm{H},{ }^{2} \mathrm{~J} \mathrm{HH}=15.6\right.$ $\left.\mathrm{Hz}, \mathrm{H}_{\mathrm{a}}\right), 5.75\left(\mathrm{~s}, 12 \mathrm{H}, \mathrm{H}_{\mathrm{c}}\right) .{ }^{13} \mathrm{C}$ NMR $\left(62.5 \mathrm{MHz}, \mathrm{DCl} / \mathrm{D}_{2} \mathrm{O}, 35 \%\right.$ $(\mathrm{w} / \mathrm{w}))$ : $\delta 51.55\left(\mathrm{CH}_{2}\right), 71.60(\mathrm{CH}), 158.1(\mathrm{C}=\mathrm{O})$. Molar mass of $\mathrm{C}_{36} \mathrm{H}_{36} \mathrm{O}_{12} \mathrm{~N}_{24}$ : 996.8418. MS (FAB + ve): $\mathrm{m} / \mathrm{z} 997[\mathrm{M}+\mathrm{H}]^{+}$, $1019[\mathrm{M}+\mathrm{Na}]^{+}, 1035[\mathrm{M}+\mathrm{K}]^{+}$. Anal. Calcd for $\mathrm{C}_{36} \mathrm{H}_{36} \mathrm{O}_{12} \mathrm{~N}_{24}{ }^{\circ}$ 2.5 $\mathrm{H}_{2} \mathrm{O}$ : C, 41.50; H, 3.96; N, 32.26. Found: C, 41.38; H, 3.93; $\mathrm{N}, 31.86$.

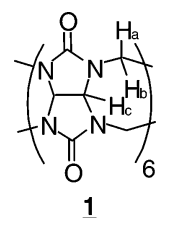

$\mathbf{N}^{1}, \mathbf{N}^{6}$-Bis(2-azidoethyl)-1,6-hexanediamine Dihydrochloride (5). 2 (2.50 g, $12.2 \mathrm{mmol}$ ) and thionyl chloride (25 $\mathrm{mL}$ ) were heated to reflux for $100 \mathrm{~min}$. The reaction mixture was allowed to cool to room temperature before excess thionyl chloride was removed under reduced pressure. The resulting dark brown residue was washed with 2-propanol. The dark colored powder was filtered off and recrystallized from 2-pro- panol to yield $\mathbf{3}$ as a light brown solid, used without further purification.Yield (crude): $2.5 \mathrm{~g}(65 \%) .{ }^{1} \mathrm{H}$ NMR $(250 \mathrm{MHz}$, $\left.\mathrm{D}_{2} \mathrm{O}\right): \delta 1.40,(\mathrm{~m}, 4 \mathrm{H}, \mathrm{e}), 1.65(\mathrm{~m}, 4 \mathrm{H}, \mathrm{d}), 3.05(\mathrm{t}, 4 \mathrm{H}, 3 \mathrm{\jmath} \mathrm{нн}=$ $7.1 \mathrm{~Hz}, \mathrm{c}), 3.45\left(\mathrm{t}, 4 \mathrm{H},{ }^{3} \mathrm{HH}_{\mathrm{H}}=5.4 \mathrm{~Hz}, \mathrm{a}\right), 3.80\left(\mathrm{t}, 4 \mathrm{H},{ }^{3} \mathrm{JHH}_{\mathrm{H}}=5.4\right.$ $\mathrm{Hz}, \mathrm{b})$.

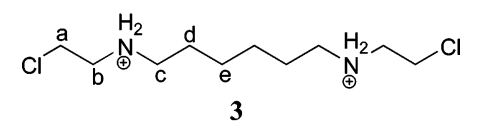

Compound 3 ( $1.73 \mathrm{~g}, 5.54 \mathrm{mmol}$ ) and sodium azide ( $1.00 \mathrm{~g}$, $15.4 \mathrm{mmol})$ were dissolved in water $(25 \mathrm{~mL})$. The light yellow solution was heated to $75^{\circ} \mathrm{C}$ under vigorous stirring overnight. Sodium hydroxide pellets $(0.50 \mathrm{~g}, 12.5 \mathrm{mmol})$ were added, and the solution was stirred for $1 \mathrm{~h}$. The precipitate was filtered off and the filtrate extracted with diethyl ether $(4 \times 25 \mathrm{~mL})$. The combined organic layers were washed with saturated $\mathrm{NaCl}$ solution $(30 \mathrm{~mL})$ and dried over anhydrous $\mathrm{MgSO}_{4} . \mathrm{N}^{1}, \mathrm{~N}^{6}$-Bis(2-azidoethyl)-1,6-hexanediamine (4) was isolated as a pale yellow oil after removal of the solvent under reduced pressure. Yield (crude): $0.66 \mathrm{~g}(60 \%)$.

The oil was dissolved in ethanol $(5 \mathrm{~mL})$, and a $1 \mathrm{~N}$ solution of $\mathrm{HCl}$ in ether was added dropwise. After $3 \mathrm{~h}$ of stirring at room temperature the precipitated white solid was filtered off. Recrystallization from ethanol/toluene (50:50 (v/v)) yiel ded light yellow, microcrystalline 5. Yield: 0.75 (84\%). IR (Nujol mull, KBr, cm-1): $3585(\mathrm{w}), 3392(\mathrm{~m}), 3158(\mathrm{~m}), 2438(\mathrm{~m}), 2105$ (s), 2088 (vs). ${ }^{1} \mathrm{H}$ NMR (250 MHz, $\left.\mathrm{D}_{2} \mathrm{O}\right): \delta 1.35(\mathrm{~m}, 4 \mathrm{H}, \mathrm{e})$, $1.65(\mathrm{~m}, 4 \mathrm{H}, \mathrm{d}), 3.05\left(\mathrm{t}, 4 \mathrm{H},{ }^{3} \mathrm{~J} \mathrm{HH}=7.1 \mathrm{~Hz}, \mathrm{c}\right), 3.15(\mathrm{t}, 4 \mathrm{H}, 5.4$ $\mathrm{Hz}, \mathrm{a}), 3.75\left(\mathrm{t}, 4 \mathrm{H}, 3_{\mathrm{HH}}=5.4 \mathrm{~Hz}, \mathrm{~b}\right) .{ }^{13} \mathrm{C}$ NMR $(100 \mathrm{MHz}$, $\mathrm{D}_{2} \mathrm{O}$ ): $\delta 28.07$ (e), 28.11 (d), 49.08 (c), 49.76 (a), 50.39 (b). Molar mass of $\mathrm{C}_{10} \mathrm{H}_{24} \mathrm{Cl}_{2} \mathrm{~N}_{8}$ : 327.26. MS (EI): $\mathrm{m} / \mathrm{z} 256(\mathrm{M}-2 \mathrm{Cl})$. Anal. Calcd: C, 36.70; H, 7.39; N, 34.24. Found: C, 36.81; H, 7.52; N, 34.50.

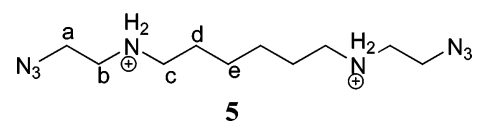

Attempted Polymerization of Monomers 5 and 6 (See Table 1). [Entry A (Table 1)] 1 (32.2 mg, $31.0 \mu \mathrm{mol})$ was dissolved in $\mathrm{DCl}\left(1 \mathrm{~mL}, 20 \mathrm{wt} \% \mathrm{DCl}\right.$ in $\left.\mathrm{D}_{2} \mathrm{O}\right)$ and the solution stirred for $30 \mathrm{~min} .5$ (4.9 mg, $16 \mu \mathrm{mol})$ was added, and the solution was stirred vigorously at room temperature for another $10 \mathrm{~min}$ before the addition of alkyne $6(4.0 \mathrm{mg}, 16$ $\mu \mathrm{mol}$ ). The resulting solution was stirred at $20^{\circ} \mathrm{C}$ for $24 \mathrm{~h}$. The reaction was monitored by ${ }^{1} \mathrm{H} N \mathrm{NMR}$.

Spectroscopic Data. [Entries A-C (Table 1), pseudorotaxanes 9 and 10] ${ }^{1} \mathrm{H}$ NMR $\left(250 \mathrm{MHz}, \mathrm{D}_{2} \mathrm{O}\right): \delta 0.45(\mathrm{~m}, 8 \mathrm{H}$, $5+\mathrm{e}), 0.75(\mathrm{~m}, 8 \mathrm{H}, 4+\mathrm{d}), 2.95\left(\mathrm{t}, 8 \mathrm{H},{ }^{3} \mathrm{H} \mathrm{H}=6.5 \mathrm{~Hz}, 3+\mathrm{c}\right)$, $3.15\left(\mathrm{t}, 2 \mathrm{H},{ }^{2} \mathrm{~J} \mathrm{нн}=2.5 \mathrm{~Hz}, 1\right), 3.35(\mathrm{t}, 4 \mathrm{H}, 3 \mathrm{~J} \mathrm{нн}=5.5 \mathrm{~Hz}, \mathrm{a})$, $3.85(\mathrm{t}, 4 \mathrm{H}, 3 \mathrm{JH}=5.5 \mathrm{~Hz}, \mathrm{~b}), 4.15\left(\mathrm{~d}, 2 \mathrm{H},{ }^{2} \mathrm{~J} H \mathrm{H}=2.5 \mathrm{~Hz}, 2\right)$, $4.43(\mathrm{~d}, 24 \mathrm{H}, \mathrm{QQ}), 5.55(\mathrm{~s}, 12 \mathrm{H}, \mathrm{QQ}), 5.75(\mathrm{~d}, 12 \mathrm{H}, \mathrm{QQ}) .{ }^{13} \mathrm{C}$ NMR (62.5 MHz, D 20 ): $\delta=27.99$ (5), 28.06 (e), 28.67 (4), 29.16 (d), 39.13 (a), 49.07 (c), 49.43 (3), 50.38 (b), 50.59 (2), 54.38 (QQ), 70.98 (-CCH), $73.26(\mathrm{QQ}), 76.02$ (1), 159.19 (QQ).

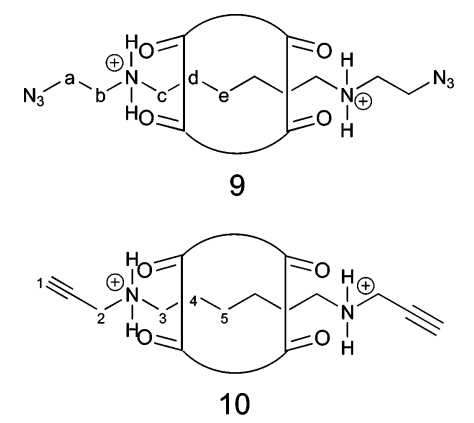

The stoichiometry between triazole protons and monomer repeat units was determined by comparing the integral of $\mathrm{H}_{8}$ with those of $\mathrm{H}_{4}+\mathrm{H}_{5}$. [Entry D (Table 1)] ${ }^{1} \mathrm{H}$ NMR $(250 \mathrm{MHz}$, 
$\left.\mathrm{D}_{2} \mathrm{O}\right): \delta 0.44(\mathrm{br} \mathrm{s}, 8 \mathrm{H}, 5), 0.70(\mathrm{br} \mathrm{s}, 8 \mathrm{H}, 4), 8.55(\mathrm{~s}, 1 \mathrm{H}, 8)$. [Entry E (Table 1)] ${ }^{1} \mathrm{H}$ NMR $\left(250 \mathrm{MHz}, \mathrm{D}_{2} \mathrm{O}\right): \delta 0.46(\mathrm{br} \mathrm{m}$, $8 \mathrm{H}, 5), 0.72(\mathrm{br} \mathrm{m}, 8 \mathrm{H}, 4), 8.51(\mathrm{~s}, 0.7 \mathrm{H}, 8)$. [E ntry F (Table 1)] ${ }^{1} \mathrm{H}$ NMR $\left(250 \mathrm{MHz}, \mathrm{D}_{2} \mathrm{O}\right): \delta 0.48(\mathrm{br} \mathrm{s}, 8 \mathrm{H}, 5), 0.75(\mathrm{br} \mathrm{s}, 8 \mathrm{H}$, 4), $8.51(\mathrm{~s}, 0.8 \mathrm{H}, 8)$.

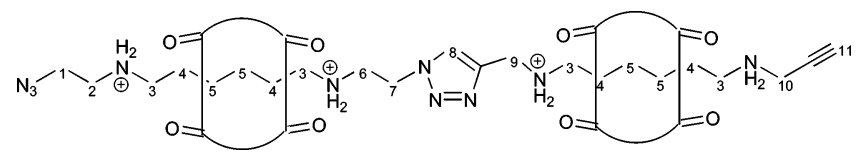

N-\{2,4,6-Trimethyl-3-[(2-propynylamino)methyl]benzyl\}-2-propyn-1-amine Dihydrochloride (14). 12 (0.51 g, $2.3 \mathrm{mmol}$ ) was added to an excess of propargylamine $(2.0 \mathrm{~mL}$, $40.6 \mathrm{mmol}$ ) at $0{ }^{\circ} \mathrm{C}$. When addition was complete, the light brown solution started to solidify within $5 \mathrm{~min}$. The solid was heated to redissolve, then refluxed for $4 \mathrm{~h}$, and finally left to stir overnight at room temperature. Excess propargylamine was distilled off at ambient pressure. The remaining brown residue was dissolved in water $(5 \mathrm{~mL})$, sodium hydroxide pellets $(0.2 \mathrm{~g}, 5.0 \mathrm{mmol})$ were added, and the suspension was stirred for 2-3 h. The aqueous layer was extracted with chloroform $(4 \times 5 \mathrm{~mL})$. The combined organic layers were washed with saturated $\mathrm{NaCl}$ solution $(10 \mathrm{~mL})$. The organic phase was dried over magnesium sulfate and filtered, and the solvent was removed under reduced pressure, yielding beige solid 13. Yield (crude): $0.55 \mathrm{~g}(100 \%)$. ${ }^{1} \mathrm{H}$ NMR $(250 \mathrm{MHz}$, $\left.\mathrm{CDCl}_{3}\right): \delta 2.29(\mathrm{t}, 2 \mathrm{H}, 4 \mathrm{~J} \mathrm{HH}=2.5 \mathrm{~Hz}, \mathrm{a}), 2.35(\mathrm{~s}, 6 \mathrm{H}, \mathrm{e}), 2.45$ $(\mathrm{s}, 3 \mathrm{H}, \mathrm{d}), 3.49\left(\mathrm{~d}, 4 \mathrm{H},{ }^{4} \mathrm{Hн}=2.5 \mathrm{~Hz}, \mathrm{~b}\right), 3.84(\mathrm{~s}, 4 \mathrm{H}, \mathrm{c}), 6.86$ $(\mathrm{s}, 1 \mathrm{H}, \mathrm{f})$.

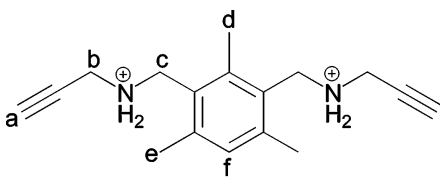

13

Crude $13(0.55 \mathrm{~g})$ was dissolved in chloroform $(5 \mathrm{~mL})$, to which a $1 \mathrm{~N}$ solution of $\mathrm{HCl}$ in diethyl ether $(4.5 \mathrm{~mL})$ was added dropwise. A dark yellow precipitate was formed immediately, and the suspension was stirred overnight. The precipitate was filtered and washed with chloroform $(5 \mathrm{~mL})$ followed by diethyl ether $(10 \mathrm{~mL})$. Recrystallization from ethanol/toluene $(80: 20(\mathrm{v} / \mathrm{v}))$ gave $\mathbf{1 4}$ as a light yellow powder. Yield: $0.60 \mathrm{~g}(86 \%) .{ }^{1} \mathrm{H}$ NMR $\left(250 \mathrm{MHz}, \mathrm{D}_{2} \mathrm{O}\right): \delta 2.30(\mathrm{~s}, 6 \mathrm{H}$, e), $2.40(\mathrm{~s}, 3 \mathrm{H}, \mathrm{d}), 3.05(\mathrm{t}, 2 \mathrm{H}, 4 \mathrm{HH}=2.5 \mathrm{~Hz}, \mathrm{a}), 4.09(\mathrm{t}, 4 \mathrm{H}$, $\left.{ }^{4} \mathrm{HH}_{\mathrm{HH}}=2.5 \mathrm{~Hz}, \mathrm{~b}\right), 4.44(\mathrm{~s}, 4 \mathrm{H}, \mathrm{c}), 7.15(\mathrm{~s}, 1 \mathrm{H}, \mathrm{f}) .{ }^{13} \mathrm{C} \mathrm{NMR}(100$ $\mathrm{MHz}, \mathrm{D}_{2} \mathrm{O}$, DSS): $\delta 18.43$ (d), 22.13 (e), 39.80 (b), 47.87 (c), 76.06 (a), 81.46 (-CCH), 129.52 (4), 134.39 (1), 141.45 (2), 143.62 (3). Molar mass of $\mathrm{C}_{17} \mathrm{H}_{24} \mathrm{Cl}_{2} \mathrm{~N}_{2}$ : 327.29. MS (FAB + ve): $\mathrm{m} / \mathrm{z} 255[\mathrm{M}-2 \mathrm{HCl}]^{+}, 291\left[\mathrm{M}-\mathrm{HCl}^{+}\right.$. Anal. Calcd for $\mathrm{C}_{17} \mathrm{H}_{26} \mathrm{~N}_{2} \mathrm{Cl}_{2} \mathrm{O}$ : C, 59.13; $\mathrm{H}, 7.59 ; \mathrm{N}$, 8.62. Found: $\mathrm{C}, 59.46 ; \mathrm{H}$, $7.61 ; \mathrm{N}, 8.79$.<smiles>C#CCNCc1c(C)c(C)c(C)c(CNCC#C)c1C</smiles>

14

N-(2-Hydroxyethyl)-N-(3-\{\{ (2-hydroxyethyl)amino]methyl\}-2,4,6-trimethylbenzyl \}amine (15). 12 (1.0 g, 4.6 $\mathrm{mmol}$ ) was added portionwise to ethanolamine $(5.6 \mathrm{~mL}, 92$ $\mathrm{mmol}$ ) over a period of $20 \mathrm{~min}$ under vigorous stirring at 120 $130^{\circ} \mathrm{C}$. The mixture was heated at $150-160^{\circ} \mathrm{C}$ for $6 \mathrm{~h}$, allowed to cool to room temperature, and then treated with a $0.05 \mathrm{~N}$ methanolic solution of $\mathrm{NaOH}(20 \mathrm{~mL})$. Then solution was cooled to $0^{\circ} \mathrm{C}$ and stirred for several hours at this temperature before the precipitated sodium chloride was filtered off. First methanol was removed from the filtrate under reduced pres- sure $(20 \mathrm{mmHg})$ at room temperature, and then excess ethanolamine was distilled off at $50{ }^{\circ} \mathrm{C}(0.8 \mathrm{mmHg})$. The remaining white solid was recrystallized from ethanol to yield 15 as a white powder. Yield: $0.80 \mathrm{~g}(66 \%) .{ }^{1} \mathrm{H}$ NMR $(250 \mathrm{MHz}$, $\left.\mathrm{D}_{2} \mathrm{O}\right): \delta 2.25(\mathrm{~s}, 6 \mathrm{H}, \mathrm{e}), 2.30(\mathrm{~s}, 3 \mathrm{H}, \mathrm{d}), 2.80(\mathrm{t}, 4 \mathrm{H}, 3 \mathrm{~J} \mathrm{нн}=7.5$ $\mathrm{Hz}, \mathrm{b}), 3.54\left(\mathrm{t}, 4 \mathrm{H},{ }^{3} \mathrm{~J} \mathrm{HH}^{2}=7.5 \mathrm{~Hz}, \mathrm{a}\right), 3.77(\mathrm{~s}, 4 \mathrm{H}, \mathrm{c}), 6.95$ (s, $1 \mathrm{H}, \mathrm{f}) .{ }^{13} \mathrm{C}$ NMR $\left(100 \mathrm{MHz}, \mathrm{D}_{2} \mathrm{O}\right): \delta 18.64$ (e), 22.24 (d), 41.77 (c), 48.23 (b), 51.83 (a), 129.43 (4), 134.44 (1), 141.50 (3), 143.60 (2). Molar mass of $\mathrm{C}_{15} \mathrm{H}_{26} \mathrm{~N}_{2} \mathrm{O}_{2}$ : 266.38. MS (FAB + ve): $\mathrm{m} / \mathrm{z}$ $267[\mathrm{M}+\mathrm{H}]^{+}$.<smiles>Cc1c(C)c(CNCCO)c(Cl)c(CNCCO)c1Cl</smiles>

15

N-(2-Chloroethyl)-N-(3-\{ (2-chloroethyl)amino]methyl $\}$ 2,4,6-trimethylamine Dihydrochloride (16). 15 (2.22 g, $8.37 \mathrm{mmol})$ was dissolved in chloroform $(25 \mathrm{~mL})$ and the solution cooled to $-10^{\circ} \mathrm{C}$. A solution of thionyl chloride $(2.50$ $\mathrm{mL}, 34.0 \mathrm{mmol}$ ) in chloroform (10 mL) was added dropwise under vigorous stirring over a period of $15 \mathrm{~min}$. The resulting white suspension was allowed to warm to room temperature and then was heated to reflux for $3 \mathrm{~h}$. During this time a light yell ow precipitate formed. The mixture was all owed to cool to room temperature before methanol $(10 \mathrm{~mL})$ was added, and the reaction mixture was stirred for a further $15 \mathrm{~min}$. Removal of the solvent under reduced pressure yielded a light yellow solid. Recrystallization from ethanol/acetone (60:40 (v/v)) gave 16 as a white powder. Yield: $1.76 \mathrm{~g}(70 \%) .{ }^{1} \mathrm{H}$ NMR $(250 \mathrm{MHz}$, $\left.\mathrm{D}_{2} \mathrm{O}\right): \delta 2.37(\mathrm{~s}, 6 \mathrm{H}, \mathrm{e}+\mathrm{f}), 2.43(\mathrm{~s}, 3 \mathrm{H}, \mathrm{d}), 3.58\left(\mathrm{t}, 4 \mathrm{H},{ }^{3} \mathrm{\textrm {Hн }}=\right.$ $5.5 \mathrm{~Hz}, \mathrm{~b}), 3.91(\mathrm{t}, 4 \mathrm{H}, 3 \mathrm{H} \mathrm{H}=5.5 \mathrm{~Hz}, \mathrm{a}), 4.55(\mathrm{~s}, 4 \mathrm{H}, \mathrm{c}), 7.14$ $(\mathrm{s}, 1 \mathrm{H}, \mathrm{g}) .{ }^{13} \mathrm{C} N \mathrm{NMR}\left(100 \mathrm{MHz}, \mathrm{D}_{2} \mathrm{O}\right): \delta 18.36$ (e), 22.10 (d), 48.18 (a), 52.08 (c), 59.08 (b), 129.88 (4), 134.28 (1), 141.28 (3), 143.29 (2). Molar mass of $\mathrm{C}_{15} \mathrm{H}_{26} \mathrm{~N}_{2} \mathrm{Cl}_{4}$ : 374.09. MS (EI): $\mathrm{m} / \mathrm{z}$ $302[\mathrm{M}-2 \mathrm{HCl}]$.<smiles>Cc1c(C)c(CNCCCl)c(Cl)c(CNCCCl)c1C</smiles>

N-(2-Azidoethyl)-N-(3-\{\{(2-azidoethyl)amino $\}$ methyl $\}$ 2,4,6-trimethylbenzyl)amine Dihydrochloride (18). Compound 16 (1.39 g, $4.60 \mathrm{mmol})$ and sodium azide (1.19 g, 18.4 $\mathrm{mmol})$ were dissolved in water $(50 \mathrm{~mL})$. The solution was heated at $75{ }^{\circ} \mathrm{C}$ overnight. Sodium hydroxide pellets $(0.81 \mathrm{~g}$, $20 \mathrm{mmol}$ ) were added neat, and the solution was stirred for an additional $2 \mathrm{~h}$. A light yellow oil formed which was extracted into chloroform $(4 \times 30 \mathrm{~mL})$. The organic phase was washed with a saturated aqueous solution of $\mathrm{NaCl}(30 \mathrm{~mL})$ and dried over anhydrous $\mathrm{MgSO}_{4}$. Diazide $\mathbf{1 7}$ was obtained as a pale yellow oil after the solvent was removed under reduced pressure. Yield (crude): 1.02 (87\%). IR (film, KBr, $\mathrm{cm}^{-1}$ ): 3328 (br), 3006 (s), 2922 (s), 2101 (vs), 1667 (m), 1451 (s). ${ }^{1} \mathrm{H}$ NMR $\left(250 \mathrm{MHz} \mathrm{CDCl}_{3}\right): \delta 2.33(\mathrm{~s}, 6 \mathrm{H}, \mathrm{e}), 2.42(\mathrm{~s}, 3 \mathrm{H}$, d), $2.90\left(\mathrm{t}, 4 \mathrm{H}, 3_{\mathrm{HH}}=5.6 \mathrm{~Hz}, \mathrm{~b}\right), 3.46\left(\mathrm{t}, 4 \mathrm{H}, 3_{\mathrm{HH}}=5.6 \mathrm{~Hz}\right.$, a), $3.77(\mathrm{~s}, 4 \mathrm{H}, \mathrm{c}), 6.95(\mathrm{~s}, 1 \mathrm{H}, \mathrm{f})$.<smiles>Cc1c(C)c(CNCCCN)c(Cl)c(CNCCN)c1Cl</smiles>

17

Compound $\mathbf{1 7}$ was dissolved in anhydrous methanol $(5 \mathrm{~mL})$. A solution of $1 \mathrm{~N}$ anhydrous $\mathrm{HCl}$ in diethyl ether $(6.5 \mathrm{~mL})$ was 
added dropwise under vigorous stirring at $0{ }^{\circ} \mathrm{C}$ over a period of $20 \mathrm{~min}$. The reaction mixture was stirred for a further $5 \mathrm{~h}$, before the solvent was removed under reduced pressure. The remaining sol id was recrystallized from ethanol to yield $\mathbf{1 8}$ as a pale yellow microcrystalline powder. Yield: $1.20 \mathrm{~g}(96 \%) .{ }^{1} \mathrm{H}$ NMR (250 MHz, $\left.\mathrm{D}_{2} \mathrm{O}\right): \delta 2.32(\mathrm{~s}, 6 \mathrm{H}, \mathrm{e}), 2.42(\mathrm{~s}, 3 \mathrm{H}, \mathrm{d}), 3.36$ (t, $\left.4 \mathrm{H}, 3 \mathrm{~J}_{\mathrm{HH}}=5.6 \mathrm{~Hz}, \mathrm{~b}\right), 3.81\left(\mathrm{t}, 4 \mathrm{H}, 3 \mathrm{~J} \mathrm{HH}^{2}=5.6 \mathrm{~Hz}, \mathrm{a}\right), 4.39$ (s, 4H, c), $7.15(\mathrm{~s}, 1 \mathrm{H}, \mathrm{f}) .{ }^{13} \mathrm{C} \mathrm{NMR}\left(100 \mathrm{MHz}, \mathrm{D}_{2} \mathrm{O}\right): \delta 18.50$ (d), 22.15 (e), 48.32 (c), 49.28 (b), 49.38 (a), 129.54 (4), 134.37 (1), 141.36 (3), 143.46 (2). Molar mass of $\mathrm{C}_{15} \mathrm{H}_{26} \mathrm{~N}_{8} \mathrm{Cl}_{2}: 389.33$. MS (FAB + ve): m/z $317\left[\mathrm{M}-2 \mathrm{HCl}^{+}, 353[\mathrm{M}-\mathrm{HCl}]^{+}\right.$. Anal. Calcd for $\mathrm{C}_{15} \mathrm{H}_{26} \mathrm{~N}_{8} \mathrm{Cl}_{2}: \mathrm{C}, 46.28 ; \mathrm{H}, 6.73 ; \mathrm{N}, 28.78$. Found: C, 46.26; $\mathrm{H}, 6.71 ; \mathrm{N}, 28.70$.

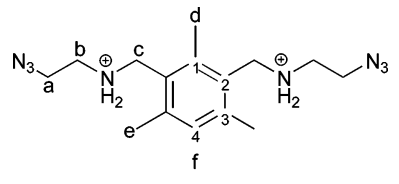

18

General Procedure for the Synthesis of Polyrotaxane 19. (Example, Table 3 , entry A) $\mathbf{1}(200 \mathrm{mg}, 200 \mu \mathrm{mol})$ was dissolved in $6 \mathrm{~N} \mathrm{HCl}(4 \mathrm{~mL})$ and the solution stirred for 30 min. Azide 18 ( $39.1 \mathrm{mg}, 100 \mu \mathrm{mol}$ ) was added under vigorous stirring at room temperature. After 10 min alkyne 14 (32.3 $\mathrm{mg}, 100 \mu \mathrm{mol}$ ) was added, upon which the suspension became homogeneous. The resulting solution was stirred at room temperature for $48 \mathrm{~h}$ (see Table 3 for reaction conditions, yield, and molar mass data (for the latter see the text for the calculation procedure)). The solution was precipitated into a large excess of acetone/ethanol (50:50, v/v) to yield a white solid, which became pale yellow during filtration. To remove excess 1, the solid was dissolved in hot water $\left(\sim 80^{\circ} \mathrm{C}\right)$ and the sol ution stirred for $2 \mathrm{~h}$. Undissol ved material was filtered off. The solvent was removed under reduced pressure to a yield col orless film, which was dried in vacuo over $\mathrm{P}_{2} \mathrm{O}_{5}$ for one week. Yield: $185 \mathrm{mg}$ (68\%). (Spectroscopic data for Table 3, entries A-P) ${ }^{1} \mathrm{H}$ NMR $\left(400 \mathrm{MHz}, \mathrm{D}_{2} \mathrm{O}\right): \delta 2.75(\mathrm{~s}, 6 \mathrm{H}, \mathrm{g}), 3.35(\mathrm{~s}, 3 \mathrm{H}$, f), $3.81(\mathrm{br}, 2 \mathrm{H}, \mathrm{d}), 4.02(\mathrm{br}, 2 \mathrm{H}, \mathrm{c}), 4.31(\mathrm{t}, 12 \mathrm{H}, \mathrm{QQ}), 4.52(\mathrm{~s}$, $2 \mathrm{H}, \mathrm{e}), 4.65(\mathrm{~s}, 2 \mathrm{H}, \mathrm{a}), 5.55-5.95(\mathrm{~m}, 24 \mathrm{H}, \mathrm{QQ}), 6.54(\mathrm{~s}, \mathrm{XH}$, b), $7.21(\mathrm{~s}, 1 \mathrm{H}, \mathrm{h}) .{ }^{13} \mathrm{C}$ NMR $\left(100 \mathrm{MHz}, \mathrm{D}_{2} \mathrm{O}+\mathrm{DSS}\right): \delta 18.96$ (g), 19.09 (g), 22.65 (f), 22.77 (f), 42.63-42.84 (d), 43.17-43.39 (c), 49.22-49.45 (a), 51.05-51.28 (e), 54.15 (QQ), 54.33 (QQ), 73.16 (QQ), $122.73(\mathrm{Tr},=\mathrm{CH}), 129.86$ (4), 130.17 (2), 133.01(1), 142.17 (3), 143.52 ( $\mathrm{Tr},=\mathrm{CR}), 159.28-159.38$ (QQ).

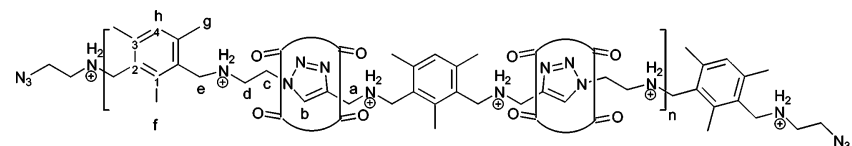

19

Counterion Exchange of Polyrotaxane 19. Polyrotaxane 19 (Table 3, entry F) $(50 \mathrm{mg})$ was dissolved in water $(3 \mathrm{~mL})$, to which a saturated solution of ammonium hexafluorophosphate was added dropwise. U pon addition the clear solution turned cloudy. Addition continued until no further precipitate was formed. Then the suspension was stirred at room temperature for 3-4 h. Filtration proved too difficult; therefore, the solvent was removed under reduced pressure, and the resulting solid was triturated with water $(3 \mathrm{~mL})$ to remove excess salt. The resulting pale yellow sticky solid was dried in vacuo. Counterion-exchanged polyrotaxane 19 was soluble in DMF, DMSO, and DMF.

[2]R otaxane 20. $1(200.0 \mathrm{mg}, 200.0 \mu \mathrm{mol})$ was dissolved in $6 \mathrm{~N} \mathrm{HCl}(5 \mathrm{~mL})$ and the solution stirred at room temperature for $30 \mathrm{~min} .22$ (36.0 mg, $200 \mu \mathrm{mol})$ was added under vigorous stirring followed by $\mathbf{2 3}$ ( $30.0 \mathrm{mg}, 200 \mu \mathrm{mol}$ ). The clear solution was stirred at room temperature for $72 \mathrm{~h}$. After removal of the solvent under reduced pressure, the remaining white solid was suspended in hot water $\left(5 \mathrm{~mL}, \sim 80^{\circ} \mathrm{C}\right)$ for 1 h. Undissolved cucurbituril was removed by filtration. The filtrate was precipitated into a large excess of acetone, upon which a white precipitate was formed. It was filtered off, washed with acetone $(10 \mathrm{~mL})$, and dried in vacuo over $\mathrm{P}_{2} \mathrm{O}_{5}$ for one week to afford 20. Yield $\left(20+9 \mathrm{H}_{2} \mathrm{O}\right)$ : $190 \mathrm{mg}(71 \%)$. ${ }^{1} \mathrm{H}$ NMR $\left(250 \mathrm{MHz}, \mathrm{D}_{2} \mathrm{O}\right): \delta 1.61(\mathrm{~s}, 9 \mathrm{H}$, e or f), $1.64(\mathrm{~s}, 9 \mathrm{H}$, e or f), $3.56\left(\mathrm{t}, 2 \mathrm{H}, 3_{\mathrm{HH}}^{3}=6.3 \mathrm{~Hz}, \mathrm{a}\right), 3.87\left(\mathrm{t}, 2 \mathrm{H},{ }^{3} \mathrm{JH}=6.3 \mathrm{~Hz}\right.$, b), $4.26\left(\mathrm{dd}, 12 \mathrm{H},{ }^{2} \mathrm{HH}=15.6 \mathrm{~Hz}, \mathrm{QQ}\right), 4.26(\mathrm{~s}, 2 \mathrm{H}, \mathrm{d}), 5.49(\mathrm{~s}$, $12 \mathrm{H}, \mathrm{QQ}), 5.71\left(\mathrm{dd}, 12 \mathrm{H}, \mathrm{J}_{\mathrm{HH}}=15.6 \mathrm{~Hz}, \mathrm{QQ}\right), 6.50(\mathrm{~s}, 1 \mathrm{H}, \mathrm{c})$. ${ }^{13} \mathrm{C}$ NMR (100 MHz, $\mathrm{D}_{2} \mathrm{O}, \mathrm{DSS}$ ): $\delta 28.40$ (e or $\mathrm{f}$ ), 28.86 (e or $\mathrm{f}$ ), 39.47 (a), 43.41 (b), 50.33 (d), $54.34(\mathrm{QQ}), 61.23\left(\mathrm{C}_{\left(\mathrm{CH}_{3}\right)_{3}, \mathrm{~g} \text { or }}\right.$

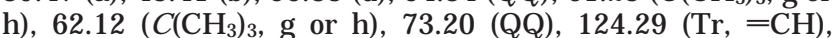
$142.65(\mathrm{Tr},=\mathrm{CR}), 159.54$ (QQ). Molar mass of $\mathrm{C}_{13} \mathrm{H}_{29} \mathrm{~N}_{5} \mathrm{Cl}_{2}$. $\left(\mathrm{C}_{36} \mathrm{H}_{36} \mathrm{O}_{12} \mathrm{~N}_{24}\right):$ 1323.16. FAB + ve MS m/z: $1251[\mathrm{M}-2 \mathrm{Cl}]^{+}$, $1287\left[\mathrm{M}-\mathrm{Cl}^{+}\right.$. Elemental analysis of $\mathrm{C}_{13} \mathrm{H}_{29} \mathrm{~N}_{5} \mathrm{Cl}_{2}$. $\left(\mathrm{C}_{36} \mathrm{H}_{36} \mathrm{O}_{12} \mathrm{~N}_{24}\right) \cdot 9 \mathrm{H}_{2} \mathrm{O}$. Calcd: C, 40.24; $\mathrm{H}, 5.16 ; \mathrm{N}, 27.81$. Found: C, 40.11; H, 5.56; N, 27.68.

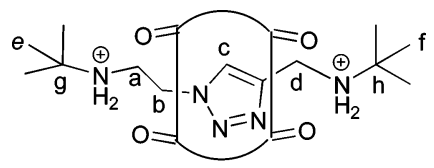

20

[3]R otaxane 21.1 (150.0 mg, $151.0 \mu \mathrm{mol})$ was dissolved in $6 \mathrm{~N} \mathrm{HCl}(4 \mathrm{~mL})$, and $22(27.0 \mathrm{mg}, 151 \mu \mathrm{mol})$ was added under vigorous stirring, followed by $\mathbf{1 4}(21.9 \mathrm{mg}, 75.0 \mu \mathrm{mol})$. The clear solution was stirred at room temperature for $72 \mathrm{~h}$. The solvent was removed under reduced pressure to yield a light yellow film, which was scraped off. The resulting powder was suspended in methanol and the suspension stirred at room temperature for $3 \mathrm{~h}$. The undissol ved residue was filtered off, washed with methanol $(3 \mathrm{~mL})$ and acetone $(5 \mathrm{~mL})$, and dried in vacuo. The isolated solid was suspended in hot water $(5 \mathrm{~mL})$ at $80^{\circ} \mathrm{C}$ and the suspension stirred for $1 \mathrm{~h}$ before it was filtered to remove excess cucurbituril. The solvent was removed under reduced pressure to yield $\mathbf{2 1}$ as an off-white powder, which was dried in vacuo over $\mathrm{P}_{2} \mathrm{O}_{5}$ for a week. Yield $\left(\mathbf{2 1}+21 \mathrm{H}_{2} \mathrm{O}\right)$ : $175 \mathrm{mg}(88 \%) .{ }^{1} \mathrm{H}$ NMR (250 MHz, $\left.\mathrm{D}_{2} \mathrm{O}\right): \delta 1.68(\mathrm{~s}, 18 \mathrm{H}, \mathrm{h})$, $2.68(\mathrm{~s}, 6 \mathrm{H}, \mathrm{f}), 2.98(\mathrm{~s}, 3 \mathrm{H}, \mathrm{g}), 3.81\left(\mathrm{t}, 4 \mathrm{H}, \mathrm{3}_{\mathrm{HH}}=8.0 \mathrm{~Hz}, \mathrm{a}\right)$, $4.03\left(\mathrm{t}, 4 \mathrm{H}, 3^{3} \mathrm{HH}=8.0 \mathrm{~Hz}, \mathrm{~b}\right), 4.30(\mathrm{dd}, 24 \mathrm{H}, \mathrm{QQ}+\mathrm{s}, 4 \mathrm{H}, \mathrm{d})$, $4.85(\mathrm{~s}, 4 \mathrm{H}, \mathrm{e}), 5.59(\mathrm{~s}, 24 \mathrm{H}, \mathrm{QQ}), 5.73(\mathrm{t}, 24 \mathrm{H}, \mathrm{QQ}), 6.54(\mathrm{~s}$, $2 \mathrm{H}, \mathrm{c}), 7.29(\mathrm{~s}, 1 \mathrm{H}, \mathrm{h}) .{ }^{13} \mathrm{C} N \mathrm{NMR}\left(100 \mathrm{MHz}, \mathrm{D}_{2} \mathrm{O}\right): \delta 20.54(\mathrm{~g})$, $29.16(\mathrm{~h}), 42.91(\mathrm{a}), 42.83(\mathrm{~b}), 49.17$ (d), $50.67(\mathrm{e}), 54.32(\mathrm{QQ})$, 54.50 (QQ), 62.74 (i), $72.91(\mathrm{QQ}), 73.03(\mathrm{QQ}), 124.05(\mathrm{Tr},=\mathrm{CH})$, 130.22 ( $\left.\mathrm{Ar}, \mathrm{C}_{4}\right), 134.49\left(\mathrm{Ar}, \mathrm{C}_{1}\right), 141.86\left(\mathrm{Ar}, \mathrm{C}_{2}+\mathrm{C}_{6}\right), 142.75$ $\left(\mathrm{Ar}, \mathrm{C}_{3}+\mathrm{C}_{5}\right), 143.28$ ( $\mathrm{Tr}$, =CR), 159.36 (QQ), 159.71 (QQ). Molar mass of $\mathrm{C}_{29} \mathrm{H}_{54} \mathrm{~N}_{10} \mathrm{Cl}_{4} \cdot\left(\mathrm{C}_{36} \mathrm{H}_{36} \mathrm{O}_{12} \mathrm{~N}_{24}\right)_{2}$ : 2678.32. MS (ES): $\mathrm{m} / \mathrm{z} 2536.50[\mathrm{M}-4 \mathrm{Cl}]^{+}, 2573.10[\mathrm{M}-3 \mathrm{Cl}]^{+}$. Anal. Calcd for $\mathrm{C}_{29} \mathrm{H}_{54} \mathrm{~N}_{10} \mathrm{Cl}_{4} \cdot\left(\mathrm{C}_{36} \mathrm{H}_{36} \mathrm{O}_{12} \mathrm{~N}_{24}\right)_{2} \cdot 21 \mathrm{H}_{2} \mathrm{O}: \mathrm{C}, 39.42 ; \mathrm{H}, 5.39 ; \mathrm{N}$, 26.91. Found: C, 39.69; H, 5.54; N, 26.58.

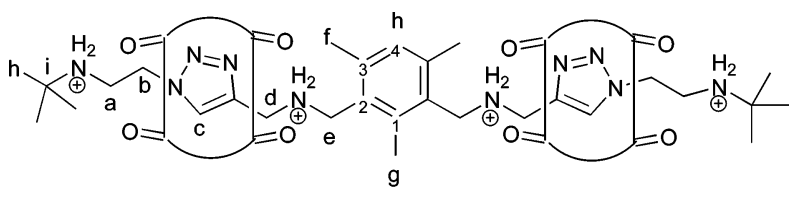

21

$\mathbf{N}$-\{2,4,6-Trimethyl-3,5-bis[(2-propynylamino)methyl]benzyl\}-2-propyn-1-amine Trihydrochloride (25). 2,4,6Tris(bromomethyl)mesitylene $(1.0 \mathrm{~g}, 2.5 \mathrm{mmol})$ was added portionwise to propargylamine $(3.4 \mathrm{~mL}, 50 \mathrm{mmol})$ at $0{ }^{\circ} \mathrm{C}$ over a period of $30 \mathrm{~min}$. A dark red solid was obtained, which was allowed to warm to room temperature and subsequently heated to reflux for $24 \mathrm{~h}$. After excess propargylamine was distilled off at ambient pressure, the dark red residue was suspended in chloroform ( $5 \mathrm{~mL}$ ), and $1 \mathrm{~N}$ aqueous $\mathrm{NaOH}$ (8 $\mathrm{mL}$ ) was added. The layers were separated after the suspension was stirred for $4 \mathrm{~h}$. The aqueous phase was extracted with $\mathrm{CHCl}_{3}(4 \times 5 \mathrm{~mL})$. The combined organic layers were washed with saturated aqueous $\mathrm{NaCl}$ solution and dried over anhydrous $\mathrm{MgSO}_{4}$. The solvent was removed from the filtrate under 
reduced pressure to yield the triamine as a red brown oily residue. Yield (crude): $0.90 \mathrm{~g}(100 \%) .{ }^{1} \mathrm{H}$ NMR $(250 \mathrm{MHz}$, $\left.\mathrm{CDCl}_{3}\right): \delta 1.06(\mathrm{br}, 3 \mathrm{H}, \mathrm{NH}), 2.36(\mathrm{t}, 3 \mathrm{H}, 4 \mathrm{JH}=2.5 \mathrm{~Hz}, \mathrm{a})$, $2.45(\mathrm{~s}, 9 \mathrm{H}, \mathrm{d}), 3.50\left(\mathrm{~d}, 6 \mathrm{H}, \mathrm{J}_{\mathrm{HH}}=2.5 \mathrm{~Hz}, \mathrm{~b}\right), 3.86(\mathrm{~s}, 6 \mathrm{H}, \mathrm{c})$.

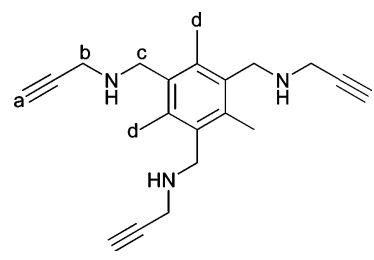

The crude triamine was dissolved in dry $\mathrm{CHCl}_{3}(5 \mathrm{~mL})$, and a solution of anhydrous $1 \mathrm{~N} \mathrm{HCl}$ in diethyl ether $(11 \mathrm{~mL})$ was added dropwise over a period of $15 \mathrm{~min}$. The brown colored reaction mixture was stirred overnight. A light brown precipitate was filtered off and washed with diethyl ether $(10 \mathrm{~mL})$. Recrystallization from ethanol/toluene $(80: 20(\mathrm{v} / \mathrm{v})$ ) yielded 25 as a light orange solid. Yield: $0.95 \mathrm{~g}(88 \%)$. ${ }^{1} \mathrm{H}$ NMR $(250 \mathrm{M} \mathrm{Hz}$, $\left.\mathrm{D}_{2} \mathrm{O}\right): \delta 2.49(\mathrm{~s}, 9 \mathrm{H}, \mathrm{d}), 3.06(\mathrm{t}, 3 \mathrm{H}, 4 \mathrm{~J} \mathrm{H}=2.5 \mathrm{~Hz}, \mathrm{a}), 4.04(\mathrm{t}$, $6 \mathrm{H}$, 4 $\mathrm{HH}=2.5 \mathrm{~Hz}, \mathrm{~b}), 4.54(\mathrm{~s}, 6 \mathrm{H}, \mathrm{c}) .{ }^{13} \mathrm{C} \mathrm{NMR}(100 \mathrm{MHz}$, $\left.\mathrm{D}_{2} \mathrm{O}\right): \delta 19.53(\mathrm{~d}), 39.98(\mathrm{~b}), 48.25(\mathrm{c}), 75.99(\mathrm{a}), 81.70(-\mathrm{CCH})$, 131.02 (1), 144.06 (2). Molar mass of $\mathrm{C}_{21} \mathrm{H}_{31} \mathrm{~N}_{3} \mathrm{Cl}_{4}$ : 429.15. MS (FAB + ve): $\mathrm{m} / \mathrm{z} 322[\mathrm{M}-3 \mathrm{HCl}]^{+}, 358[\mathrm{M}-2 \mathrm{HCl}]^{+}$. Anal. Calcd for $\mathrm{C}_{21} \mathrm{H}_{31} \mathrm{~N}_{3} \mathrm{Cl}_{4}$ : C, 58.54; $\mathrm{H}, 7.02 ; \mathrm{N}, 9.75$. Found: C, 58.38; $\mathrm{H}, 6.93 ; \mathrm{N}, 9.73$.

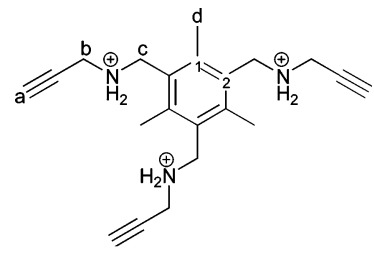

25

General Procedure for the Synthesis of Branched Polyrotaxane 26. (Example, Table 5, entry D) 1 (300 mg, 300 $\mu \mathrm{mol})$ was dissolved in $6 \mathrm{~N} \mathrm{HCl}(5 \mathrm{~mL})$ under vigorous stirring. Alkyne 25 (43.1 mg, $100 \mu \mathrm{mol})$ was added to yield a yellow colored solution, which was stirred at room temperature for 1 $\mathrm{h}$ before the addition of azide $18(38.9 \mathrm{mg}, 100 \mu \mathrm{mol})$. The resulting solution was heated at $60{ }^{\circ} \mathrm{C}$ for $192 \mathrm{~h}$. Precipitation into acetone/ethanol $(25 \mathrm{~mL}, 50: 50(\mathrm{v} / \mathrm{v}))$ yielded a white solid which became slightly sticky and yellow colored during suction filtration. The solid was dried in vacuo over $\mathrm{P}_{2} \mathrm{O}_{5}$ for one week. Yield: $308 \mathrm{mg}, 78 \%$. See the text for a discussion of ${ }^{1} \mathrm{H}$ NMR and MALDI-TOF data.

Acknowledgment. We thank the EPSRC for providing an I PSI project studentship for D.T. Thanks are also due to Dr. Welham of the University of London ULIRS service for carrying out MALDI-TOF spectrometry, Dr. Ball for providing us with ES mass spectrometry data, and the EPSRC RAPRA service for GPC characterization data.

\section{References and Notes}

(1) Gibson, H. W.; Bheda, M. C.; Engen, P. T. Prog. Polym. Sci. 1994, 19, 843.

(2) Panova, I. G.; Topchieva, I. N. Russ. Chem. Rev. 2001, 70, 23.

(3) Amabilino, D. B.; Parsons, I. W.; Stoddart, J. F. Trends Polym. Sci. 1994, 2, 146.

(4) Gong, C.; Gibson, H. W. Curr. Opin. Solid State Mater. Sci. 1997, 2, 647

(5) Gong, C.; Gibson, H. W. Mol. Catenanes, Rotaxanes Knots 1999, 277.

(6) Gibson, H. W.; Liu, S. Macromol. Symp. 1996, 102, 55

(7) Fujita, H.; Ooya, T.; Yui, N. Macromol. Chem. Phys. 1999, 200,706
(8) I keda, T.; Watabe, N.; Ooya, T.; Yui, N. Macromol. Chem. Phys. 2001, 202, 1338

(9) Fujita, H.; Ooya, T.; Yui, N. Macromolecules 1999, 32, 2534.

(10) Herrmann, W.; Schneider, M.; Wenz, G. Angew. Chem., Int. Ed. Engl. 1997, 36, 2511.

(11) Yamaguchi, I.; Osakada, K.; Yamamoto, T. Chem. Commun. 2000, 1335.

(12) Von Kieckebusch-Guck, A. Schweiz. Lab.-Z. 2000, 57, 40.

(13) Ikeda, T.; Ooya, T.; Yui, N. Polym. J . 1999, 31, 658

(14) Ooya, T.; Yui, N. ACS Symp. Ser. 2000, 752, 375.

(15) Huh, K. M.; Tomita, H.; Lee, W. K.; Ooya, T.; Yui, N Macromol. Rapid Commun. 2002, 23, 179.

(16) Olson, K.; Chen, Y. Y.; Baker, G. L. J . Polym. Sci., Part A: Polym. Chem. 2001, 39, 2731.

(17) Gong, C. G.; Balanda, P. B.; Gibson, H. W. Macromolecules 1998, 31, 5278 .

(18) Gibson, H. W.; Liu, S.; Gong, C.; J i, Q.; J oseph, E. Macromolecules 1997, 30, 3711.

(19) Shen, Y. X.; Xie, D.; Gibson, H. W. J . Am. Chem. Soc. 1994 $116,537$.

(20) Nagapudi, K.; Leisen, J .; Beckham, H. W.; Gibson, H. W. Macromol ecules 1999, 32, 3025.

(21) Loveday, D.; Wilkes, G. L.; Bheda, M. C.; Shen, Y. X.; Gibson, H. W. J. Macromol. Sci., Pure Appl. Chem. 1995, A32, 1.

(22) Nagapudi, K.; Hunt, J .; Shepherd, C.; Baker, J .; Beckham, H. W. Macromol. Chem. Phys. 1999, 200, 2541.

(23) Gong, C. G.; J i, Q.; Subramaniam, C.; Gibson, H. W Macromolecules 1998, 31, 1814.

(24) Gong, C.; Glass, T. E.; Gibson, H. W. Macromolecules 1998 $31,308$.

(25) Gong, C.; Gibson, H. W. Angew. Chem., Int. Ed. Engl. 1997 $36,2331$.

(26) Gong, C.; i, Q.; Subramaniam, C.; Gibson, H. W. Macromolecules 1998, 31, 1814.

(27) Gong, C.; Gibson, H. W. J . Am. Chem. Soc. 1997, 119, 8585.

(28) Cacialli, F.; Wilson, J . S.; Michels, J .J .; Daniel, C.; Silva, C.; Friend, R. H.; Severin, N.; Samori, P.; Rabe, J . P.; O'Connell, M. J .; Taylor, P. N.; Anderson, H. L. Nat. Mater. 2002, 1, 160.

(29) Watanabe, J .; Ooya, T.; Park, K. D.; Kim, Y. H.; Yui, N. J. Biomater. Sci., Polym. Ed. 2000, 11, 1333.

(30) Lee, J. W.; Choi, S.; Ko, Y. H.; Kim, S. Y.; Kim, K. Bull. Korean Chem. Soc. 2002, 23, 1347.

(31) Ooya, T.; Yui, N. Crit. Rev. Ther. Drug Carrier Syst. 1999, 16, 289.

(32) Ooya, T.; Yui, N. Macromol. Chem. Phys. 1998, 199, 2311.

(33) Ooya, T.; Eguchi, M.; Ozaki, A.; Yui, N. Int. J . Pharm. 2002, $242,47$.

(34) Ooya, T.; Yui, N. J . Controlled Release 1999, 58, 251.

(35) Harrison, I. T. J . Chem. Soc., Perkin Trans. 1 1974, 301.

(36) Harrison, I. T. J . Chem. Soc., Chem. Commun. 1972, 231.

(37) Perez-Alvarez, M.; Raymo, F. M.; Rowan, S. J .; Schiraldi, D.; Stoddart, J . F.; Wang, Z. H.; White, A. J . P.; Williams, D. J Tetrahedron 2001, 57, 3799.

(38) Chiu, S. H.; Rowan, S. J .; Cantrill, S. J .; Ridvan, L.; Ashton, P. R.; Garrell, R. L.; Stoddart, J . F. Tetrahedron 2002, 58, 807.

(39) Sohgawa, Y.-H.; Fujimori, H.; Shoji, J .; Furusho, Y.; Kihara, N.; Takata, T. Chem. Lett. 2001, 774.

(40) Cantrill, S. J .; Youn, G. J .; Stoddart, J . F.; Williams, D. J . J Org. Chem. 2001, 66, 6857.

(41) Rowan, S. J .; Cantrill, S. J .; Stoddart, J . F.; White, A. J . P.; Williams, D. J . Org. Lett. 2000, 2, 759.

(42) Gibson, H. W.; Engen, P. T. New J . Chem. 1993, 17, 723.

(43) Gibson, H. W.; Nagvekar, D. S.; Powell, J .; Gong, C. G.; Bryant, W. S. Tetrahedron 1997, 53, 15197.

(44) Meschke, C.; Buschmann, H. J .; Schollmeyer, E. Polymer 1999, 40, 945

(45) Harada, A.; Li, J.; Kamachi, M. Nature 1992, 356, 325.

(46) Harada, A. Coord. Chem. Rev. 1996, 148, 115.

(47) Okumura, H.; Kawaguchi, Y.; Harada, A. Macromolecules 2001, 34, 6338.

(48) Tuncel, D.; Steinke, J. H. G. Chem. Commun. 2001, 253.

(49) Wenz, G.; Keller, B. Angew. Chem., Int. Ed. Engl. 1992, 31, 197.

(50) Hodge, P.; Monvisade, P.; Owen, G. J .; Heatley, F.; Pang, Y. New J . Chem. 2000, 24, 703.

(51) Owen, G. J .; Hodge, P. Chem. Commun. 1997, 11.

(52) Mason, P. E.; Parsons, I. W.; Tolley, M. S. Polymer 1998, 39 , 3981.

(53) Gong, C. G.; Gibson, H. W. Macromol. Chem. Phys. 1997, 198 2321. 
(54) Mason, P. E.; Bryant, W. S.; Gibson, H. W. Macromolecules 1999, 32, 1559.

(55) Harada, A.; Li, J .; Kamachi, M. Nature 1993, 364, 516.

(56) Watanabe, J .; Ooya, T.; Yui, N. J . Biomater. Sci., Polym. Ed. 1999, 10, 1275.

(57) Gibson, H. W.; Bheda, M.; Engen, P. T.; Shen, Y. X.; Sze, J .; Wu, C.; J oardar, S.; Ward, T. C.; Lecavalier, P. R. Makromol. Chem., Macromol. Symp. 1991, 42-3, 395.

(58) Gibson, H. W.; Lee, S. H.; Engen, P. T.; Lecavalier, P.; Sze J .; Shen, Y. X.; Bheda, M. J . Org. Chem. 1993, 58, 3748.

(59) Gibson, H. W.; Engen, P. T.; Lee, S. H. Polymer 1999, 40, 1823.

(60) Taylor, P. N.; O'Connell, M. J .; McNeill, L. A.; Hall, M. j.; Aplin, R. T.; Anderson, H. L. Angew. Chem., Int. Ed. 2000, 39, 3456.

(61) Lee, S. H.; Engen, P. T.; Gibson, H. W. Macromol ecules 1997, 30, 337.

(62) Kawaguchi, Y.; Harada, A. J . Am. Chem. Soc. 2000, 122, 3797.

(63) Gong, C.; J i, Q.; Glass, T. E.; Gibson, H. W. Macromolecules 1997, 30, 4807.

(64) Yamaguchi, I.; Osakada, K.; Yamamoto, T.J . Am. Chem. Soc. 1996, 118, 1811.

(65) Gibson, H. W.; Bheda, M. C. Polymer 1995, 36, 2615.

(66) Gong, C. G.; Gibson, H. W. Macromolecules 1996, 29, 7029.

(67) Glink, P. T.; Oliva, A. I.; Stoddart, J. F.; White, A. J . P.; Williams, D. J . Angew. Chem. 2001, 40, 1870.

(68) Seel, C.; Vögtle, F. Chem.-Eur. J . 2000, 6, 21.

(69) Yamagishi, T.-A.; Kawahara, A.; Kita, J .; Hoshima, M.; Umehara, A.; Ishida, S.-I.; Nakamoto, Y. Macromol ecules 2001, 34, 6565 .

(70) Ashton, P. R.; Belohradsky, M.; Philp, D.; Spencer, N.; Stoddart, J . F. J . Chem. Soc., Chem. Commun. 1993, 1274.

(71) Raymo, F. M.; Houk, K. N.; Stoddart, J . F. J . Am. Chem. Soc. 1998, 120, 9318.

(72) Macartney, D. H. J . Chem. Soc., Perkin Trans. 2 1996, 2775.

(73) Raymo, F. M.; Stoddart, J . F. Pure Appl. Chem. 1997, 69, 1987.

(74) Amabilino, D. B.; Asakawa, M.; Ashton, P. R.; Ballardini, R.; Balzani, V.; Belohradsky, M.; Credi, A.; Higuchi, M.; Raymo, F. M.; Shimizu, T.; Stoddart, J . F.; Venturi, M.; Yase, K. New J. Chem. 1998, 22, 959.

(75) Sohgawa, Y. H.; Fujimori, H.; Shoji, J .; Furusho, Y.; Kihara, N.; Takata, T. Chem. Lett. 2001, 774.

(76) Furusho, Y.; Hasegawa, T.; Tsuboi, A.; Kihara, N.; Takata, T. Chem. Lett. 2000, 18.

(77) Oku, T.; Furusho, Y.; Takata, T. J . Polym. Sci., Part A: Polym. Chem. 2003, 41, 119.

(78) Behrend, R.; Meyer, E.; Rusche, F. Liebigs Ann. Chem. 1905, 339, 1.

(79) Freeman, W. A.; Mock, W. L.; Shih, N. Y. J . Am. Chem. Soc. 1981, 103, 7367.

(80) Mock, W. L.; Shih, N. Y. J . Org. Chem. 1983, 48, 3618.

(81) Mock, W. L.; Irra, T. A.; Wepsiec, J . P.; Manimaran, T. L. J . Org. Chem. 1983, 48, 3619.

(82) Mock, W. L.; Manimaran, T.; Freeman, W. A.; Kuksuk, R. M.; Maggio, J . E.; Williams, D. H. J . Org. Chem. 1985, 50, 60.

(83) Mock, W. L.; Shih, N. Y.J . Org. Chem. 1986, 51, 4440.

(84) Mock, W. L.; Shih, N. Y. J . Am. Chem. Soc. 1988, 110, 4706.

(85) Mock, W. L.; Shih, N. Y.J . Am. Chem. Soc. 1989, 111, 2697.

(86) Mock, W. L.; Irra, A.; Websiec, J . P.; Adhya, M. J . Org. Chem. 1989, 54, 5302.

(87) Mock, W. L.; Irra, T. A.; Wepsiec, J . P.; Adhya, M. J . Org. Chem. 1989, 54, 5302.

(88) Mock, W. L.; Pierpont, J . J . Chem. Soc., Chem. Commun. 1990, 1509.

(89) Mock, W. L. Top. Curr. Chem. 1995, 175, 1.

(90) Buschmann, H.J .; Schollmeyer, E.J . Inclusion Phenom. Mol. Recognit. Chem. 1992, 14, 91

(91) Buschmann, H. J .; Cleve, E.; Schollmeyer, E. Inorg. Chim. Acta 1992, 193, 93.

(92) Flinn, A.; Hough, G. C.; Stoddart, J . F.; Williams, D. J . Angew. Chem., Int. Ed. Engl. 1992, 31, 1475.

(93) Cintas, P. J . Inclusion Phenom. Mol. Recognit. Chem. 1994, $17,205$.

(94) J eon, Y. M.; Whang, D.; Kim, J .; Kim, K. Chem. Lett. 1996, 503.

(95) J eon, Y. M.; Kim, H.; Whang, D.; Kim, K. J . Am. Chem. Soc. 1996, 118, 9790.

(96) Whang, D.; J eon, Y. M.; Heo, J .; Kim, K. J . Am. Chem. Soc. 1996, 118, 11333.
(97) Germain, P.; Letoffe, J . M.; Merlin, M. P.; Buschmann, H. J Thermochim. Acta 1998, 315, 87.

(98) Buschmann, H. J .; Wego, A.; Schollmeyer, E.; Dopp, D. Supramol. Chem. 2000, 11, 225.

(99) Isobe, H.; Tomita, N.; Lee, J. W.; Kim, H. J .; Kim, K. Nakamura, E. Angew. Chem. 2000, 39, 4257.

(100) J un, S. I.; Lee, J. W.; Sakamoto, S.; Yamaguchi, K.; Kim, K. Tetrahedron Lett. 2000, 41, 471.

(101) Kim, J .; J ung, I. S.; Kim, S. Y.; Lee, E.; Kang, J. K.; Sakamoto, S.; Yamaguchi, K.; Kim, K. J . Am. Chem. Soc. 2000, 122, 540

(102) Kim, H. J .; Heo, J .; J eon, W. S.; Lee, E.; Kim, J .; Sakamoto, S.; Yamaguchi, K.; Kim, K. Angew. Chem. 2001, 40, 1526.

(103) Krasia, T. C.; Steinke, J. H. G. Chem. Commun. 2002, 22.

(104) Park, K. M.; Whang, D.; Lee, E.; Heo, J .; Kim, K. Chem.Eur. J. 2002, 8, 498.

(105) J on, S. Y.; Ko, Y. H.; Park, S. H.; Kim, H.J .; Kim, K. Chem. Commun. 2001, 1938.

(106) Tuncel, D.; Steinke, J. H. G. Chem. Commun. 2002, 496.

(107) Kim, K. Chem. Soc. Rev. 2002, 31, 96.

(108) Marquez, C.; Nau, W. M. Angew. Chem. 2001, 40, 3155.

(109) Zhao, J. Z.; Kim, H. J .; Oh, J .; Kim, S. Y.; Lee, J. W.; Sakamoto, S.; Yamaguchi, K.; Kim, K. Angew. Chem. 2001, $40,4233$.

(110) Isobe, H.; Sato, S.; Nakamura, E. Org. Lett. 2002, 4, 1287.

(111) Kim, H. J .; J eon, W. S.; Ko, Y. H.; Kim, K. Proc. Natl. Acad. Sci. U.S.A. 2002, 99, 5007.

(112) Lim, Y. B.; Kim, S. M.; Suh, H.; Park, J . S. Bioconj. Chem. 2002, 13, 952.

(113) J eon, Y.J .; Bharadwaj, P. K.; Choi, S. W.; Lee, J . W.; Kim, K. Angew. Chem. 2002, 41, 4474.

(114) Day, A. I.; Blanch, R. J .; Arnold, A. P.; Lorenzo, S.; Lewis, G. R.; Dance, I. Angew. Chem. 2001, 41, 275.

(115) Buschmann, H. J .; Cleve, E.; J ansen, K.; Wego, A.; Schollmeyer, E. J . Inclusion Phenom. Macrocycl. Chem. 2001, 40, 117.

(116) Buschmann, H. J .; J ansen, K.; Meschke, C.; Schollmeyer, E. J. Solution Chem. 1998, 27, 135.

(117) Virovets, A. V.; Samsonenko, D. G.; Sokolov, M. N.; Fedin, V. P. Acta Crystallogr., Sect. E.: Struct. Rep. Online 2001, 57, M33.

(118) Samsonenko, D. G.; Virovets, A. V.; Sharonova, A. A.; Fedin, V. P.; Fenske, D. Russ. Chem. Bull. 2001, 50, 494.

(119) Lorenzo, S.; Day, A.; Craig, D.; Blanch, R.; Arnold, A.; Dance, I. CrystEngComm 2001, 1.

(120) Virovets, A. V.; Samsonenko, D. G.; Dybtsev, D. N.; Fedin, V. P.; Clegg, W. J . Struct. Chem. 2001, 42, 319.

(121) Meschke, C.; Buschmann, H. J .; Schollmeyer, E. Thermochim. Acta 1997, 297, 43.

(122) Buschmann, H.J .; J ansen, K.; Schollmeyer, E. Thermochim Acta 1998, 317, 95.

(123) Freeman, W. A. Acta Crystallogr., Sect. B: Struct. Sci. 1984, 40, 382.

(124) Hoffmann, R.; Knoche, W.; Fenn, C.; Buschmann, H. J . J. Chem. Soc., Faraday Trans. 1994, 90, 1507.

(125) Buschmann, H.-J .; Meschke, C.; Schollmeyer, E. An. Quim. Int. Ed. 1998, 94, 241.

(126) Hansen, J . B.; Nielsen, M. C.; Ehrbar, U.; Buchardt, O. Synthesis 1982, 404.

(127) Edwards, M. L.; Prakash, N.J .; Stemerick, D. M.; Sunkara, S. P.; Bitonti, A. J .; Davis, G. F.; Dumont, J . A.; Bey, P. J . Med. Chem. 1990, 33, 1369.

(128) Perner, T.; Schulz, R. C. Br. Polym. J . 1987, 19, 181.

(129) Choi, S.; Lee, J. W.; Ko, Y. H.; Kim, K. Macromol ecules 2002 $35,3526$.

(130) Herrmann, W.; Keller, B.; Wenz, G. Macromolecules 1997. 30, 4966

(131) Mason, P. E.; Parsons, I. W.; Tolley, M. S. Angew. Chem., Int. Ed. Engl. 1996, 35, 2238

(132) Tuncel, D.; Steinke, J. H. G. Chem. Commun. 1999, 1509.

(133) Murgasova, R.; Hercules, D. M. Int. J. Mass Spectrom. 2003, 226, 151.

(134) Macha, S. F.; Limbach, P. A. Curr. Opin. Solid State Mater. Sci. 2002, 6, 213

(135) Parker, D.; Feast, W. J . Macromolecules 2001, 34, 5792.

(136) Sunder, A.; Heinemann, J .; Frey, H. Chem.-Eur. J . 2000, 6, 2499.

(137) Vargha, L. J . Chem. Soc. 1957, 805.

(138) Forster, M. O.; N ewman, S. H. J . Chem. Soc. 1911, 99, 1277.

(139) Bannard, R. A. B.; Parkkari, J . H.; Coleman, I. W. Can. J . Chem. 1962, 40, 1909.

(140) Ben-Efraim, D. A. Tetrahedron 1973, 29, 4111.

MA034294V 